\title{
Transcriptional profiling of an Fd-GOGAT1/GLU1 mutant in Arabidopsis thaliana reveals a multiple stress response and extensive reprogramming of the transcriptome
}

Ralph Kissen ${ }^{1 \dagger}$, Per Winge ${ }^{1 \dagger}$, Diem Hong Thi Tran ${ }^{1}$, Tommy S Jørstad ${ }^{1,3}$, Trond R Størseth ${ }^{2}$, Tone Christensen ${ }^{1,4}$, Atle M Bones $^{1 *}$

\begin{abstract}
Background: Glutamate plays a central position in the synthesis of a variety of organic molecules in plants and is synthesised from nitrate through a series of enzymatic reactions. Glutamate synthases catalyse the last step in this pathway and two types are present in plants: $\mathrm{NADH}$ - or ferredoxin-dependent. Here we report a genome wide microarray analysis of the transcriptional reprogramming that occurs in leaves and roots of the $A$. thaliana mutant glu1-2 knocked-down in the expression of Fd-GOGAT1 (GLU1; At5g04140), one of the two genes of $A$. thaliana encoding ferredoxin-dependent glutamate synthase.
\end{abstract}

Results: Transcriptional profiling of glu1-2 revealed extensive changes with the expression of more than 5500 genes significantly affected in leaves and nearly 700 in roots. Both genes involved in glutamate biosynthesis and transformation are affected, leading to changes in amino acid compositions as revealed by NMR metabolome analysis. An elevated glutamine level in the glu1-2 mutant was the most prominent of these changes. An unbiased analysis of the gene expression datasets allowed us to identify the pathways that constitute the secondary response of an FdGOGAT1/GLU1 knock-down. Among the most significantly affected pathways, photosynthesis, photorespiratory cycle and chlorophyll biosynthesis show an overall downregulation in glu1-2 leaves. This is in accordance with their slight chlorotic phenotype. Another characteristic of the glu1-2 transcriptional profile is the activation of multiple stress responses, mimicking cold, heat, drought and oxidative stress. The change in expression of genes involved in flavonoid biosynthesis is also revealed. The expression of a substantial number of genes encoding stress-related transcription factors, cytochrome P450 monooxygenases, glutathione S-transferases and UDP-glycosyltransferases is affected in the glu1-2 mutant. This may indicate an induction of the detoxification of secondary metabolites in the mutant.

Conclusions: Analysis of the glu1-2 transcriptome reveals extensive changes in gene expression profiles revealing the importance of Fd-GOGAT1, and indirectly the central role of glutamate, in plant development. Besides the effect on genes involved in glutamate synthesis and transformation, the glu1-2 mutant transcriptome was characterised by an extensive secondary response including the downregulation of photosynthesis-related pathways and the induction of genes and pathways involved in the plant response to a multitude of stresses.

\footnotetext{
* Correspondence: atle.bones@bio.ntnu.no

+ Contributed equally

'Department of Biology, Norwegian University of Science and Technology

(NTNU), NO-7491 Trondheim, Norway
} 


\section{Background}

Nitrogen is an important nutrient for plants and a limiting factor in plant development. It is mainly in the form of nitrate through nitrate transporters that nitrogen is taken up by plants. Nitrate is first reduced to nitrite and subsequently to ammonium through the action of nitrate reductase (EC 1.7.1.1) and nitrite reductase (EC 1.7.7.1), respectively. Glutamine synthetase (EC 6.3.2.1) catalyses the incorporation of this ammonium into glutamate and thereby producing glutamine. Subsequently, glutamate synthase transfers the amide amino group of glutamine to 2-oxoglutarate, yielding two molecules of glutamate. Production of glutamate is a key point in the synthesis of a variety of organic molecules, such as nucleic acids, amino acids and secondary metabolites (for review: [1]; Figure 1).

Besides the function in primary nitrogen assimilation, the GS/GOGAT pathway plays a central role in the reassimilation of ammonium produced by photorespiration (for review: [2]). Photorespiration is a photosynthesis-related pathway where $\mathrm{O}_{2}$ is taken up and $\mathrm{CO}_{2}$ is released due to the oxygenation of ribulose-1,5-biphosphate $(\mathrm{RuBP})$ catalysed by RuBP carboxylase/oxygenase [3].

Plants possess two forms of glutamate synthase, which are both localized in plastids. One uses NADH as electron donor and is commonly called NADH-GOGAT (EC 1.4.1.14; GOGAT for "glutamine oxoglutarate aminotransferase"). The other one uses ferredoxin as electron donor and is called Fd-GOGAT (EC 1.4.7.1)(for

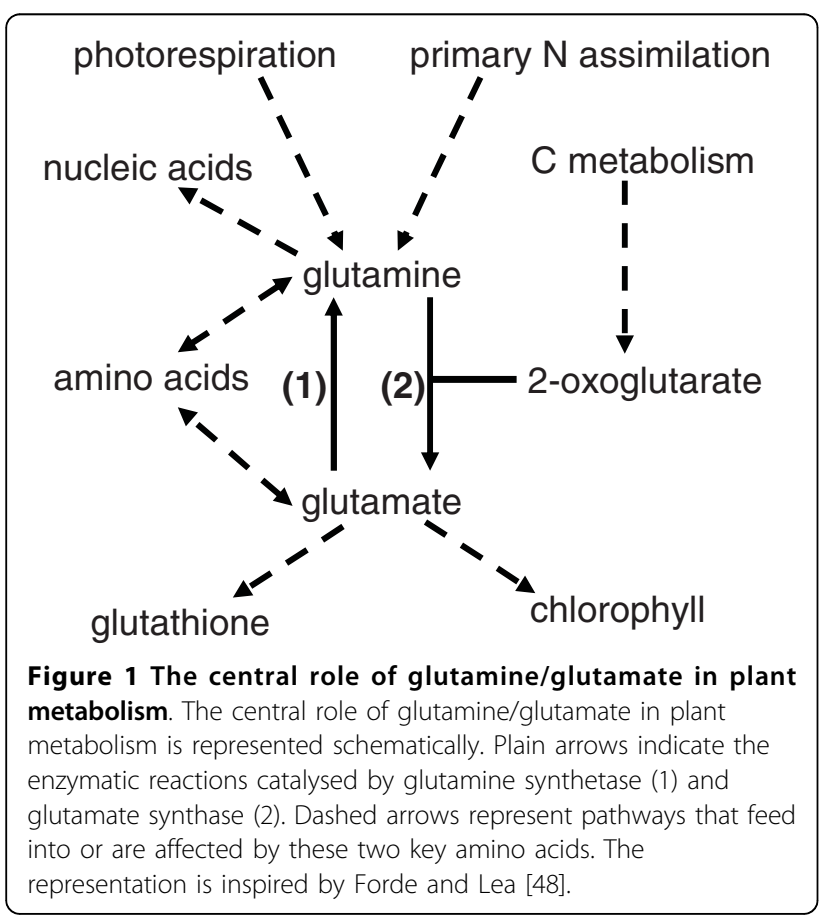

review: [4]). In Arabidopsis thaliana, NADH-GOGAT is encoded by a single gene (At5g53460) whereas FdGOGAT is encoded by two genes, previously called GLU1 (Fd-GOGAT1, At5g04140) and GLU2 (FdGOGAT2, At2g41220)[5]. The two genes encoding FdGOGAT in A. thaliana show contrasting patterns of expression, with Fd-GOGAT1 expression being highest in leaves, whereas $F d$-GOGAT2 is mostly expressed in roots [5,6]. Total glutamate synthase activity in $A$. thaliana is to a very large extent due to ferredoxin-dependent glutamate synthase, Fd-GOGAT1 contributing most [5,7]. Fd-GOGAT1 and Fd-GOGAT2 expression is also regulated differently: light causes a dramatic increase in Fd-GOGAT1 whereas Fd-GOGAT2 expression is not or only slightly affected. Similarly, $F d$ GOGAT1 but not Fd-GOGAT2 expression is induced by sucrose [5]. Both Fd-GOGATs are localized to plastids but a mitochondrial localisation of Fd-GOGAT1 has also recently been shown [8].

Plants deficient in Fd-GOGAT activity have been described in A. thaliana, under several names (gluS [9], gltS [7], gls [5], glu1 [8]), and in other species such as barley and tobacco $[10,11]$. A chlorotic phenotype and a lethal phenotype under photorespiratory conditions, which indicate the importance of glutamate synthase in the respiratory pathway, are characteristic for FdGOGAT mutants $[5,9]$.

The aim of the study was to characterise the transcriptional reprogramming that occurs in an A. thaliana mutant named glu1-2, knocked-down in the expression of Fd-GOGAT1 (GLU1; At5g04140) and to relate this to metabolic and phenotypic changes observed for this mutant.

We report here the genome wide transcriptional analysis by microarray and the metabolic profiling by NMR spectroscopy of in vitro grown glu1-2 mutant plantlets. These analyses identified substantial reprogramming of several pathways and processes in the mutant. These include primary and secondary nitrogen assimilation, leading to changes in the levels of certain amino acid, and photosynthesis related processes. The mutant was also affected in flavonoid biosynthesis and exhibited extensive transcriptional changes indicating the induction of multiple stress responses.

\section{Results and Discussion}

\section{Phenotype of the glu1-2 mutant}

An $A$. thaliana mutant presenting a T-DNA insertion in the Fd-GOGAT1 (GLU1, GLS1; At5g04140) gene was used in the present study. This mutant will hence be referred to as glu1-2 mutant hereafter. Under the in vitro growth conditions that were used in the present study, glu1-2 mutant plants exhibited a moderate 
chlorotic phenotype and reduced growth compared to wild-type Col-0 plants (Figure 2).

\section{Global overview and comparison of gene datasets that} are affected in the Fd-GOGAT1 mutant leaves and roots Changes in gene expression in leaves and roots of 18 day old in vitro grown $A$. thaliana glu1-2 plantlets were analysed using a genome wide microarray approach. This analysis showed that the expression of a high number of genes was affected in the glu1-2 mutant. Only genes whose expression was identified as being significantly changed at $\mathrm{P}=0.01$ were retained.

With 5615 genes whose expression were significantly affected (either induced or repressed) in leaves versus 687 genes in roots, there was an 8-fold difference in the number of affected genes between the two organs (Table 1 ). This was most likely due to the fact that $F d$ GOGAT1, as opposed to Fd-GOGAT2 and NADH$G O G A T$, has a much lower expression in roots than in leaves, which will be discussed later on. Some probes
Table 1 Overview of genes differentially expressed between the glu1-2 mutant and the wild-type mutant

\begin{tabular}{lll}
\hline Organ & Change in expression & Number of genes \\
\hline leaf & increased & 2957 \\
\hline leaf & reduced & $2708^{*}$ \\
\hline root & increased & 384 \\
\hline root & reduced & 303
\end{tabular}

Number of genes genes whose expression is significantly $(P=0.01)$ increased or reduced in the respective glu1-2 mutant organ versus that in wild-type. The details on the affected genes are given in Additional file 1.

*this number includes genes from mitochondrion and plastid genomes.

hybridizing to genes encoded by mitochondrial and chloroplastic genomes were found in the dataset of genes downregulated in leaves of the glu1-2 mutant. Within each organ the ratio between number of induced and the number of repressed genes was only slightly biased towards induction (1.09 in leaves and 1.27 in roots). When comparing the change fold in expression between the glu1-2 mutant and the wild-type, the $\log _{2}$ ratio of

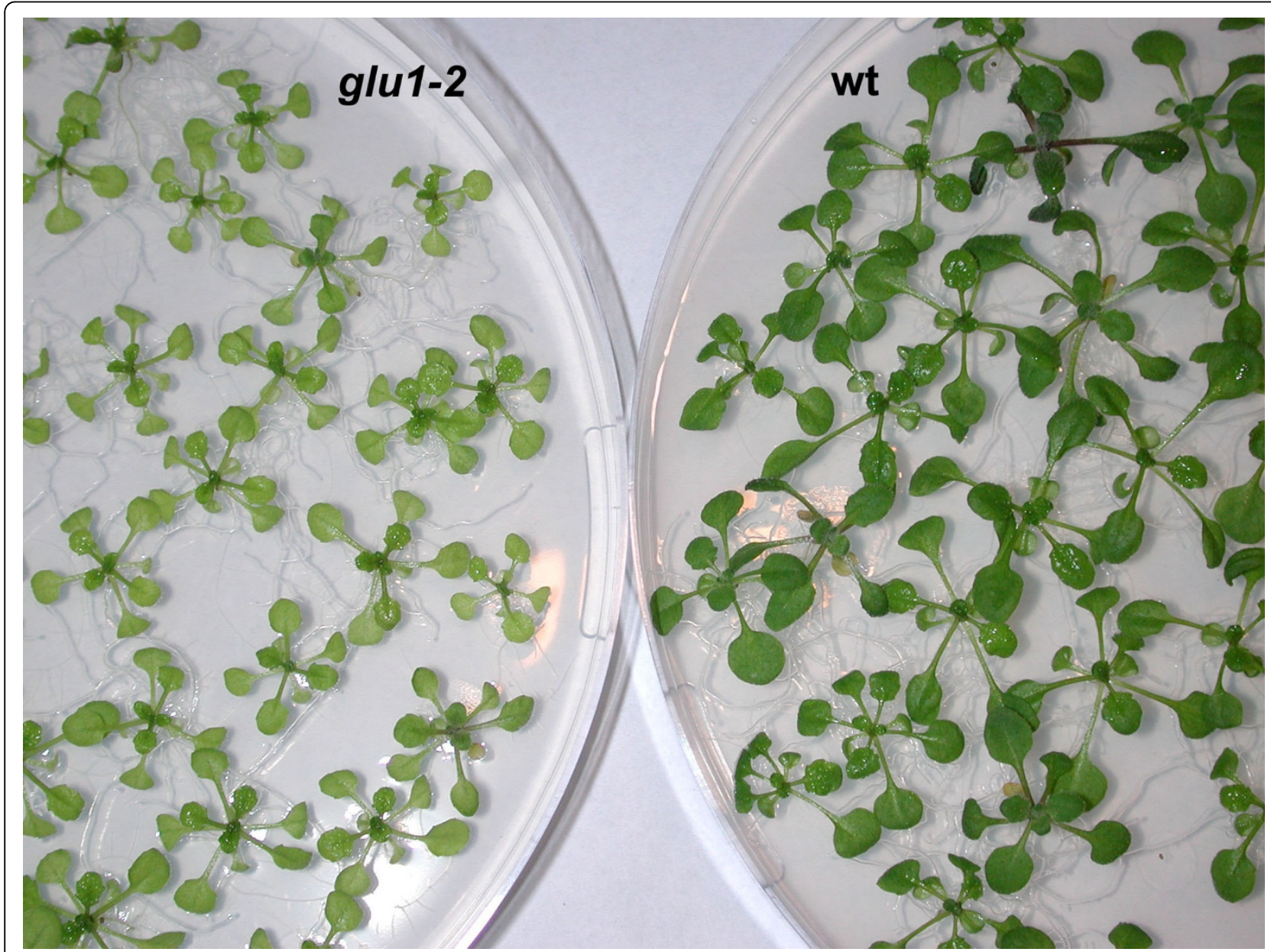

Figure 2 Chlorotic phenotype of glu1-2 mutant plants. Picture showing the chlorotic phenotype of eighteen-day old glu1-2 mutants (left) compared to Col-0 wild-type plants (right) grown in vitro. 
affected genes in leaves varied between 6.41 and -5.73 whereas that in roots was much more moderate with a variation between 1.71 and -2.61 (Additional file 1).

In glu1-2 mutant leaves, 2865 of the 2957 (almost 97\%) induced genes were exclusively affected in this tissue (Figure 3). The 92 genes whose expression was also affected in roots, were almost equally distributed between induced (50) and repressed (42). genes. Among the 2708 genes repressed in leaves, 2540 (almost 94\%) were only affected in leaves. Of the remaining 168 genes that are repressed in leaves and affected in roots, there is a clear bias towards induction. In glu1-2 roots, 228 out of 384 (over 59\%) induced genes and 199 out of 303 (over 65\%) repressed genes were exclusively affected in this tissue. Among the remaining genes, which were also affected in leaves, the induced ones were more prevalent than the repressed ones, irrespective of whether they were up-or down-regulated in leaves.

Analysis of overrepresented gene ontologies and affected pathways among affected genes in the glu1-2 mutant indicates a reprogramming of several biological processes As seen above, a large number of genes are affected in the glu1-2 mutant, notably the leaves, which indicates that a profound transcriptional reprogramming takes place. The schematic representation by Mapman [12]

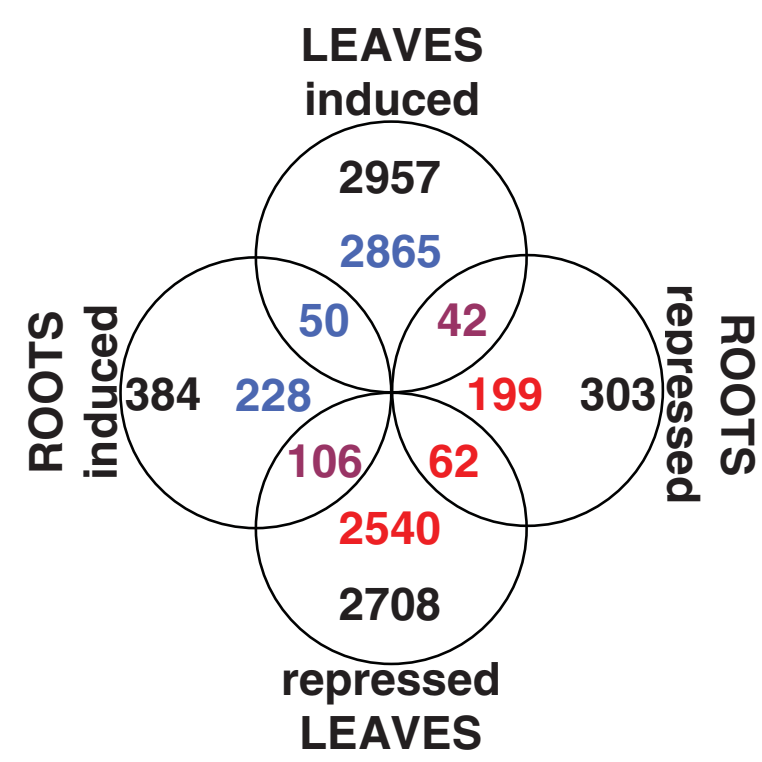

Figure 3 Overview of the transcriptional changes in the glu1-2 mutant. Venn diagram representing the genes that are significantly $(P=0.01)$ affected in the glu1-2 mutant versus wild-type plants. The total number of genes induced or repressed in leaves or roots are indicated in black. Induced genes are indicated in blue and repressed genes are indicated in red. Genes that are affected in both roots and leaves but show differential regulation are indicated in violet. illustrates to what extent different cellular processes and metabolic pathways are affected in the glu1-2 mutant (Figure 4). In order to identify the most relevant ones, an unbiased analysis of affected gene ontologies (GOs) and pathways was performed.

An analysis of overrepresented GO terms of the "biological process" classification using GOstat $[13](\mathrm{P}=0.01$ level with FDR/Benjamini correction) on the different glu1-2 transcriptional datasets was performed. The results of this analysis are shown in detail in Additional file 2 and summarised below.

When this analysis is applied to the genes whose expression is affected in glu1-2 leaves, not discriminating between induced and repressed ones, 54 overrepresented GO_biological_process terms are identified. When the datasets are separated into genes induced or repressed in glu1-2 leaves, 73 and 19 overrepresented GO terms are identified respectively. In comparison, only 13 GO_biological_process terms are overrepresented among the affected (induced or repressed) genes in glu1-2 roots. Analysis on glu1-2 root-induced and -repressed genes separately identifies 34 and 0 overrepresented GO_biological_process terms, respectively. When combining expression patterns from leaves and roots $2 \mathrm{GO}$ _biological_process terms are overrepresented among affected genes, while the subset of genes downregulated in leaves and upregulated in roots reveals three additional overrepresented GO_biological_processes. Two terms are overrepresented among genes induced in both organs of the glu1-2 mutant (Additional file 2).

Hence, GOstat identifies in total 124 unique GO_biological_process terms (confounded levels) that are overrepresented in the glu1-2 transcriptional profile changes (Additional file 2). Analysis with two further algorithms, PathExpress [14] and GeneBins [15], gave overlapping results to the ones obtained by GOstat as to which biological processes and pathways are affected in the glu1-2 mutant. These results are therefore not further detailed in the text but are shown in Additional files 3 and 4.

Visualisation of the networks of GO terms that are enriched in the glu1-2 mutant versus wild-type, using the Cytoscape [16] plug-in ClueGO [17], illustrates the complexity of the transcriptional response in glu1-2 mutant leaves (Figures 5 and 6). Notably, among genes upreglated in glu1-2 leaves GO terms related to metabolic processes of nitrogen and carbohydrate compounds (Figure 5), the regulation of transcription and the response to a diversity of stimuli are overrepresented. GO categories related to the latter two are also overrepresented among downregulated genes in glu1-2 leaves, in addition to photosynthesis and pigment/porphyrin biosynthesis (Figure 6). Although the complexity of GO-term networks enriched in the glu1-2 mutant roots versus wild-type roots is reduced (Figure 7 ), the 


\section{A leaves}

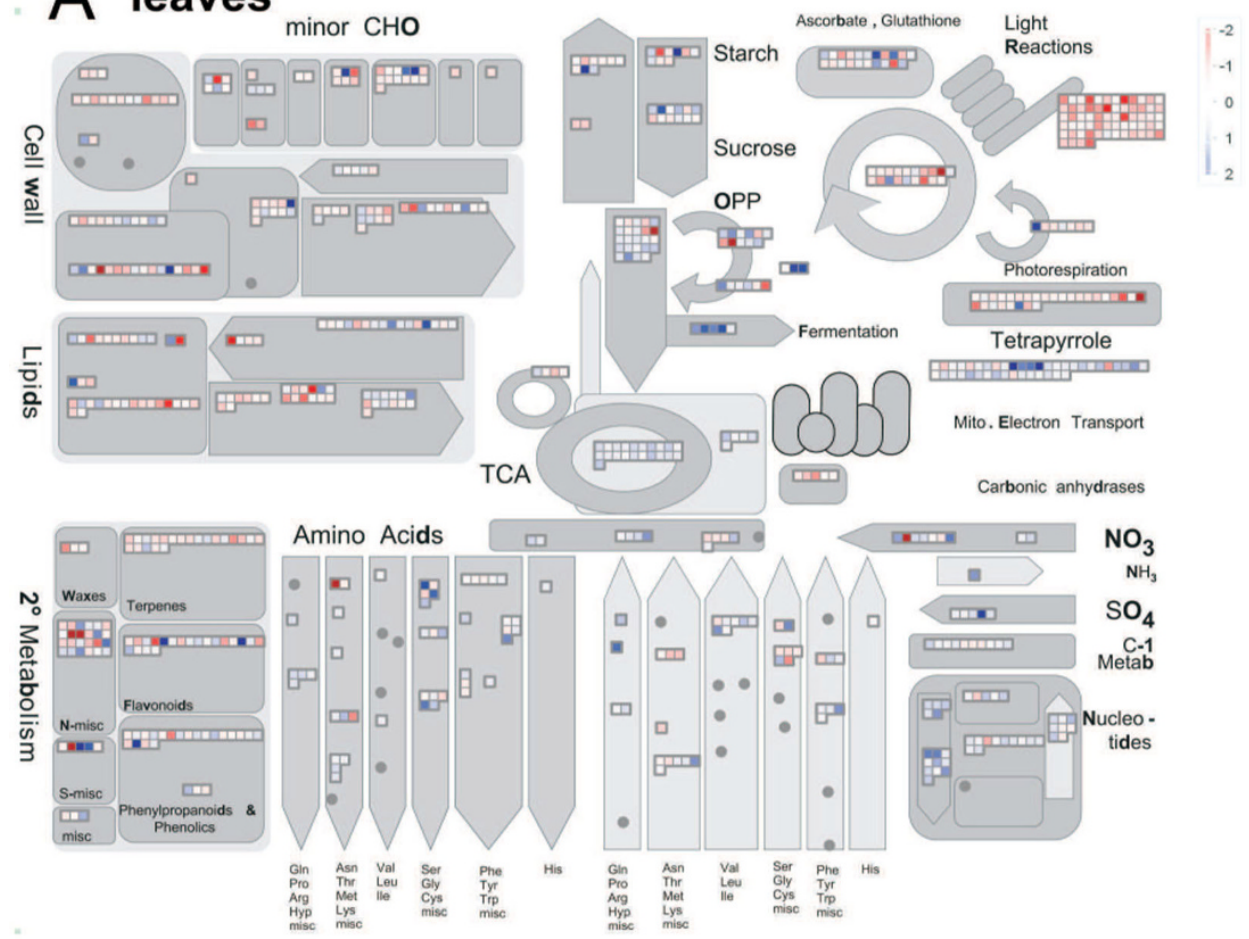

\section{$B$ roots}
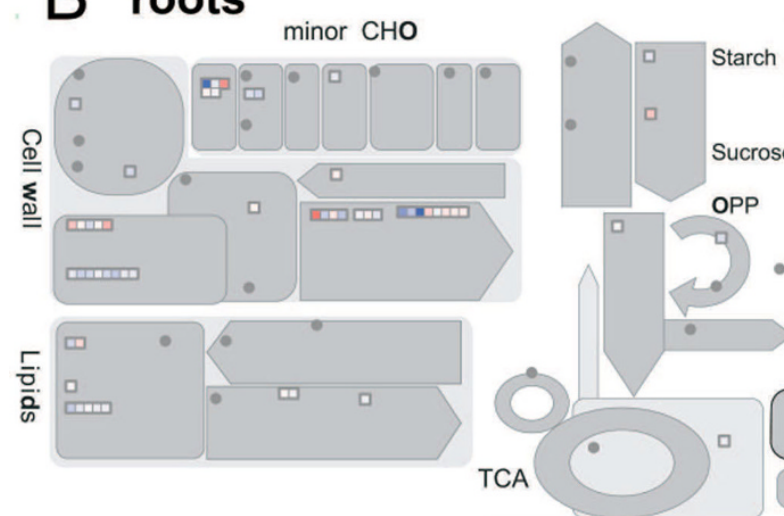

Ascorbate, Glutathione Light
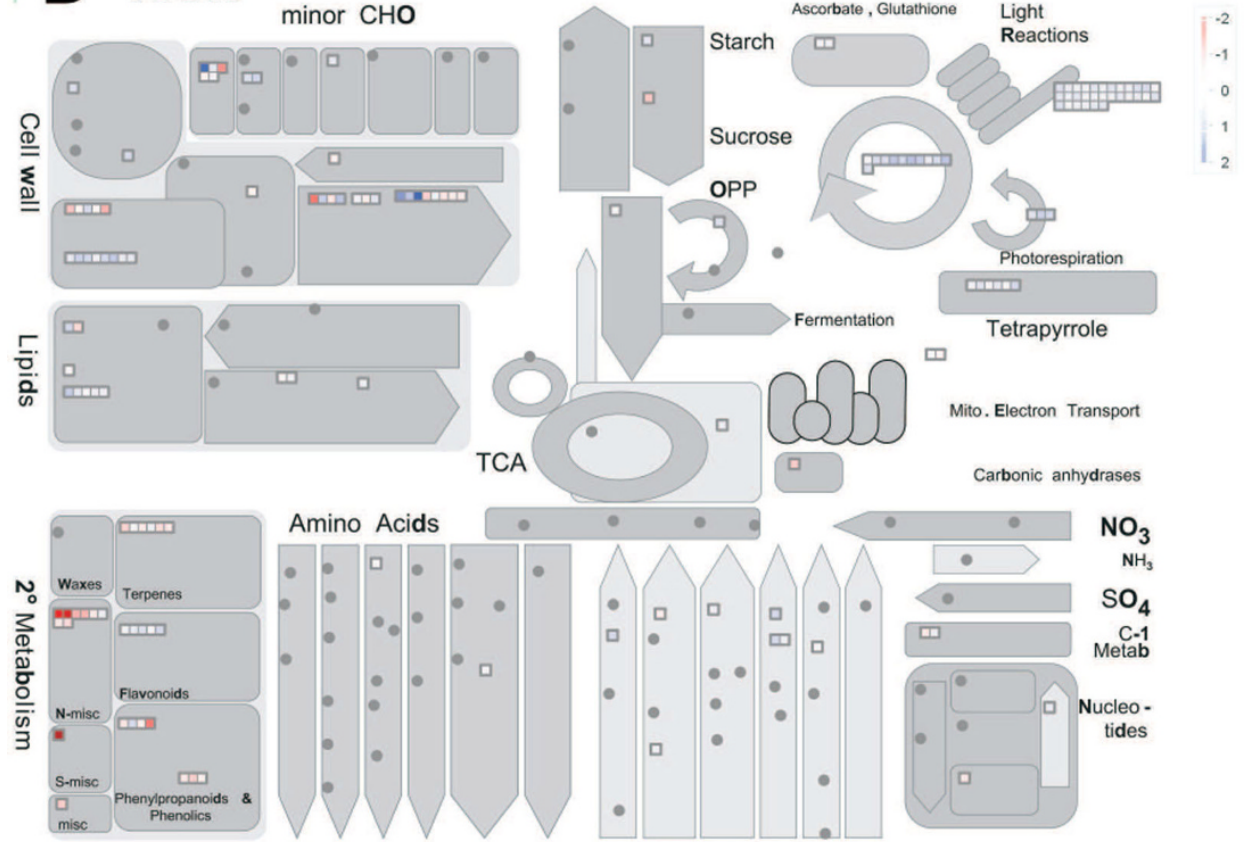

Carbonic anhydrases



Figure 4 Metabolic pathways covered by the transcriptional changes affecting the glu1-2 mutant. Overview of expression changes in metabolic pathways in glu1-2 mutant leaves (A) and roots (B) using the MapMan software [12]. Represented are only the genes showing a significant $(P=0.01)$ change in expression between the glu1-2 mutant and the wild-type and that have been attributed to the respective bins by MapMan. Genes whose expression is increased or decreased in the glu1-2 mutant tissue versus the corresponding wild-type tissue are shown by an increasingly intense blue and red colour, respectively. The graduation can be seen on the scale that is represented in the top right corner of each subfigure. A change in expression of $\log _{2}=2.0$ scale was chosen as giving full saturation. 


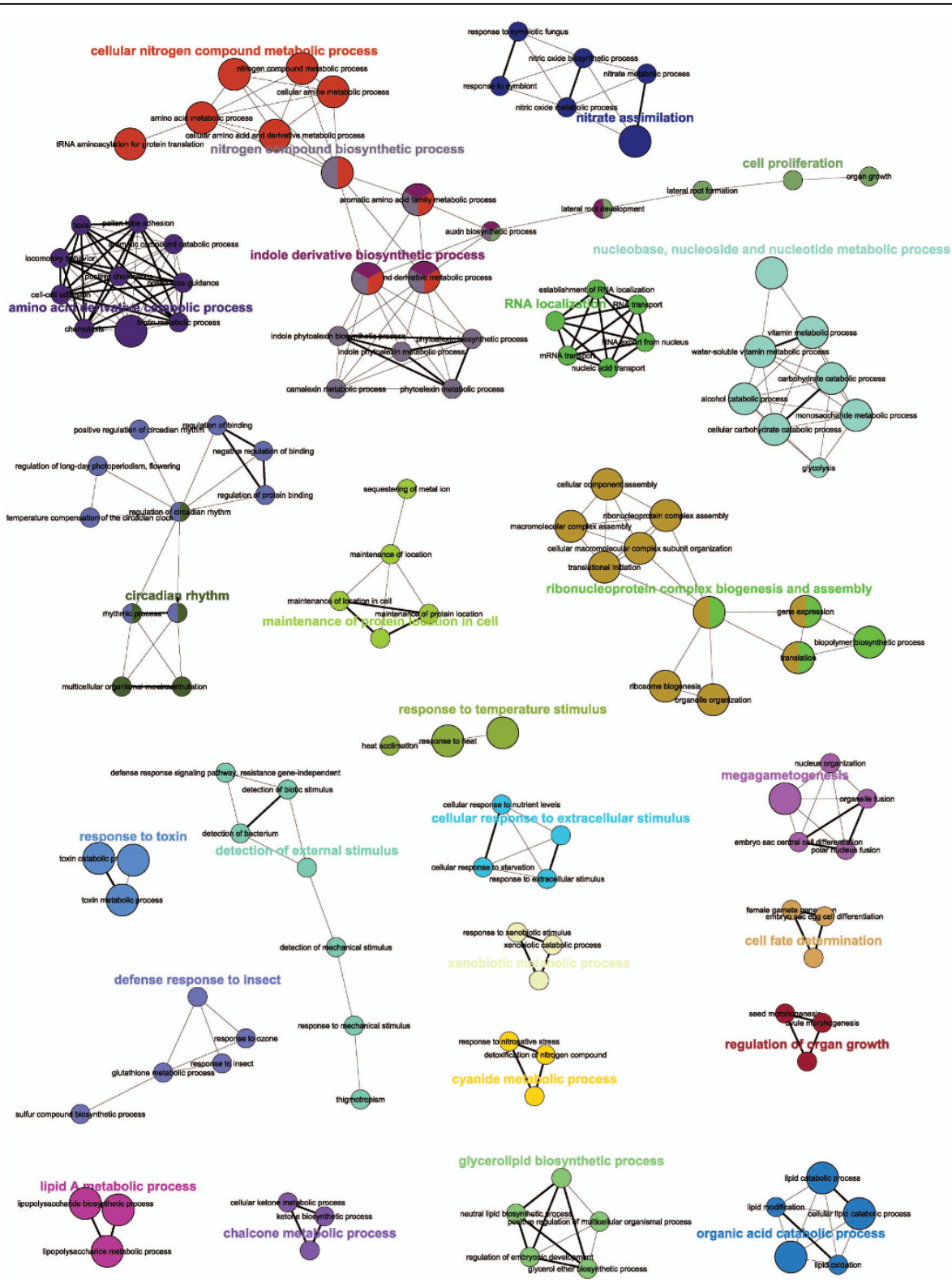

Figure 5 Network representations of enriched GO categories amongst genes induced in glu1-2 mutant leaves. Representations generated by ClueGO [17] of functionally grouped networks of enriched GO categories among genes whose expression is induced in leaves of the glu1-2 mutant compared to leaves of the wild-type. GO terms are represented as nodes based on their kappa score level ( $\geq 0.3)$, only networks with at least three nodes being represented. The node size represents the term enrichment significance. The label of the most significant term is used as leading group term.

T-DNA insertion in Fd-GOGAT1 has nevertheless a considerable impact on the root transcriptome as evidenced by the number of affected genes (i.e. 687) and the affected GO-terms (Additional files 2 to 4 ).

The large number of genes with modified expression and the analyses described above indicate that a large number of pathways and processes are seemingly affected in the glu1-2 mutant. Interestingly, glutamate biosynthesis and nitrogen metabolism are not often identified as such, and if so are indicated as induced in leaves. However as these pathways most likely constitute the plant's primary response to the knock-down of $F d$ GOGAT1, the expression data of genes involved in these pathways will be analysed in a first part. In a second part the focus will be put on some of the processes that, despite the differences in algorithms and category definitions and terms, are recurrently identified by the performed analyses. These processes most likely constitute 


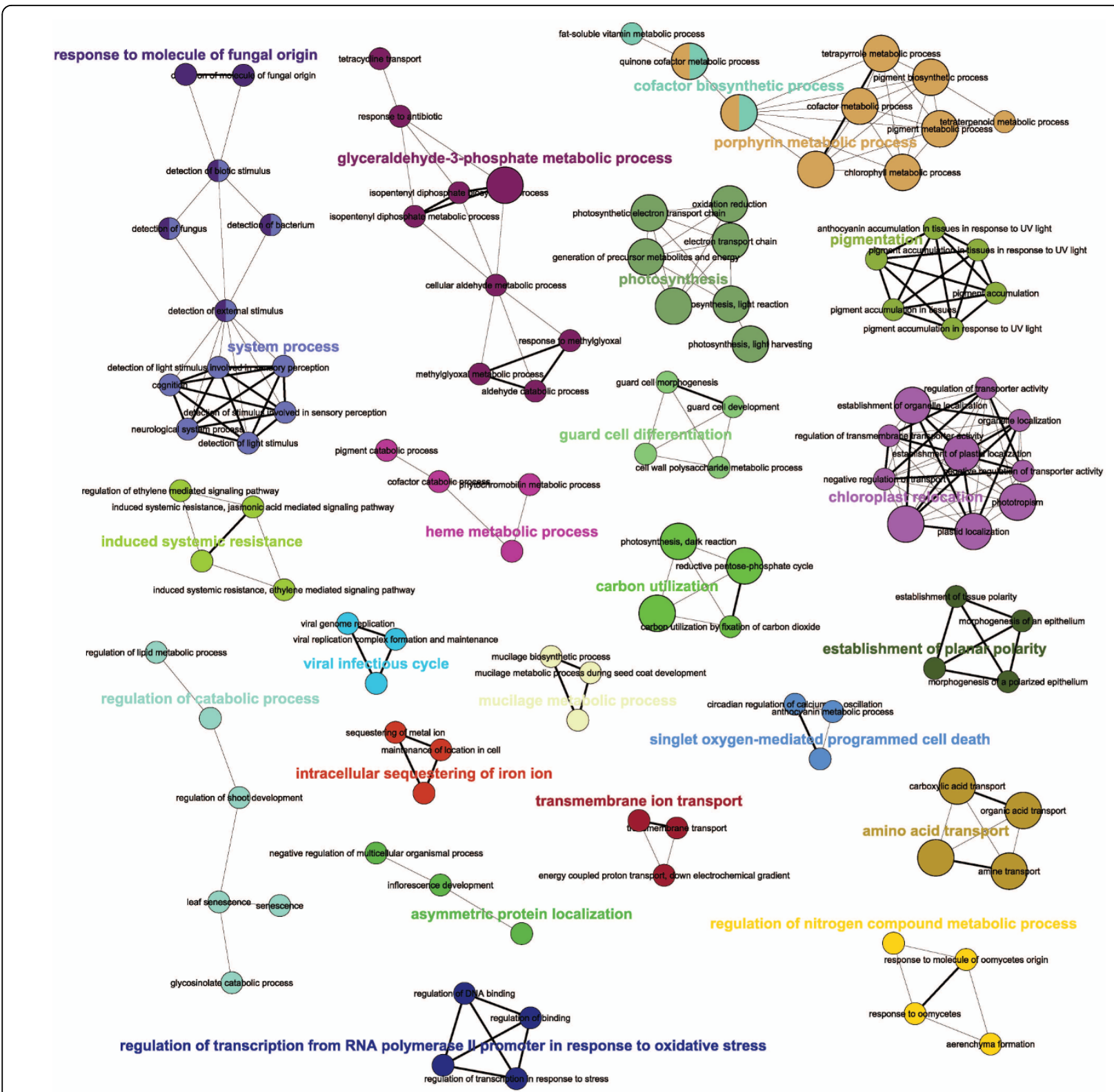

Figure 6 Network representations of enriched GO categories amongst genes repressed in glu1-2 mutant leaves. Representations generated by ClueGO [17] of functionally grouped networks of enriched GO categories among genes whose expression is repressed in leaves of the glu 1-2 mutant compared to leaves of the wild-type. GO terms are represented as nodes based on their kappa score level ( $\geq 0.3)$, only networks with at least three nodes being represented. The node size represents the term enrichment significance. The label of the most significant term is used as leading group term.

a secondary response of the mutant plant and encompass photosynthesis and related processes as well as aspects of a multiple stress response.

Even within the selected pathways and processes that will be presented below it is out of scope to present and discuss all aspects in the text. The reader is therefore kindly referred to the respective Additional files containing the detailed information about affected genes.
Analysis of genes involved in glutamate biosynthesis or related pathways whose expression is affected in leaves or roots of the glu1-2 mutant

Changes in expression levels of genes involved in glutamate biosynthesis and related pathways

In order to show how glutamate metabolism and related pathways are affected in the glu1-2 mutant, an overview of the major genes and enzymes involved (Table 2) is 


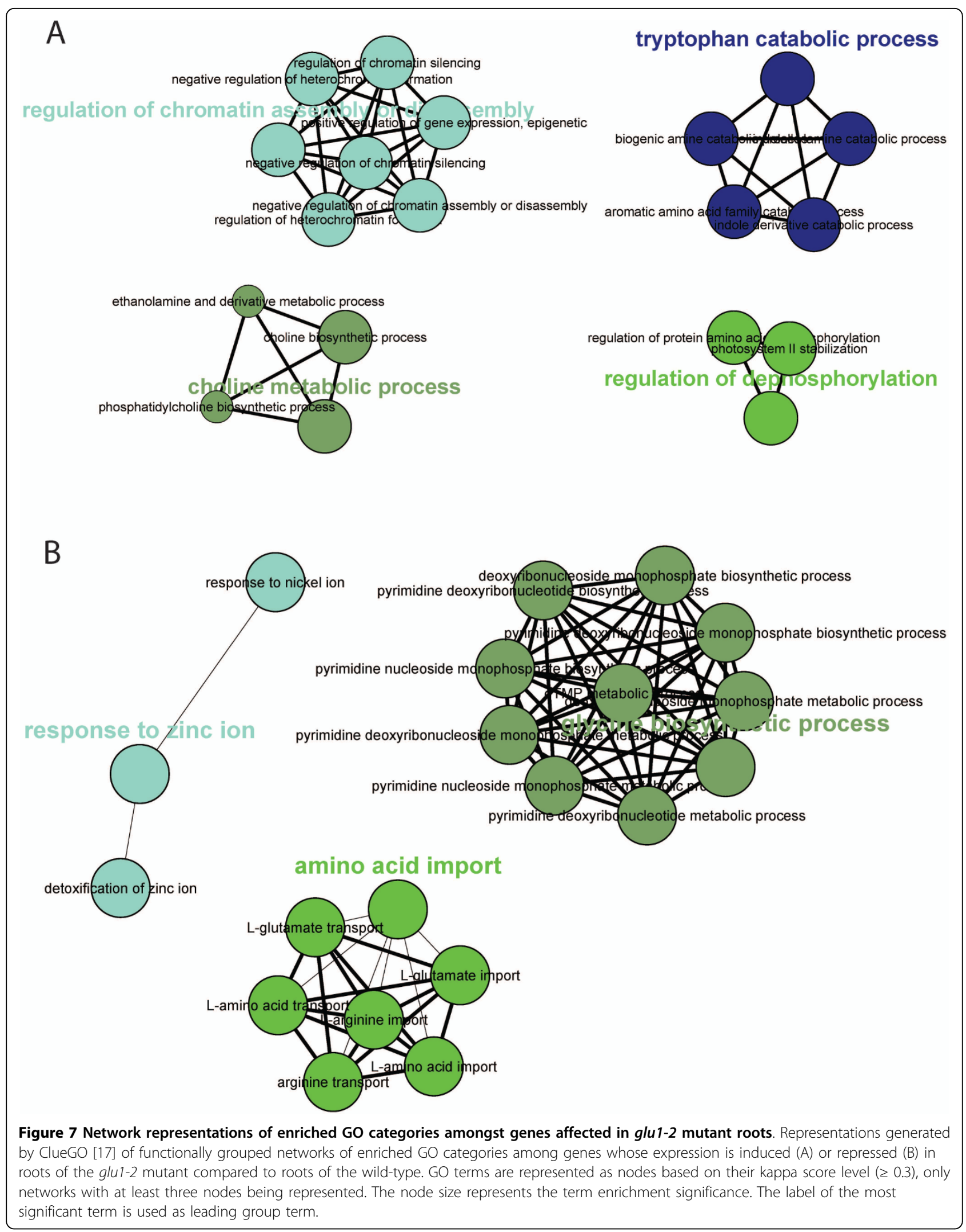


Table 2 Genes that are involved in major glutamate-related pathways and that are differentially expressed between the glu1-2 mutant and the wild-type mutant

\begin{tabular}{|c|c|c|c|c|c|}
\hline EC \# & Enzyme/protein & Abbreviation & Gene ID & $\log _{2}$ root & $\log _{2}$ leaf \\
\hline 1.4.1.7 & Fd-dependent glutamate synthase & Fd-GOGAT 1/GLU1 & AT5G04140 & & -5.738 \\
\hline$\overline{1.4 .1 .7}$ & Fd-dependent glutamate synthase & Fd-GOGAT 2/GLU2 & AT2G41220 & & 1.070 \\
\hline 1.4 .1 .14 & NADH-dependent glutamate synthase & NADH-GOGAT & AT5G53460 & & 0.712 \\
\hline 1.7 .1 .1 & nitrate reductase & $\mathrm{NIA} 2 / \mathrm{NR} 2$ & AT1G37130 & & 0.438 \\
\hline 1.7 .7 .1 & nitrite reductase & NIR1 & AT2G15620 & & 0.687 \\
\hline 6.3 .1 .2 & glutamine synthetase & GLN1.1 & AT5G37600 & & 1.296 \\
\hline 6.3 .1 .2 & glutamine synthetase & GLN1.3 & AT3G17820 & & 0.669 \\
\hline 6.3 .1 .2 & glutamine synthetase & GLN1.4 & AT5G16570 & & -0.580 \\
\hline 6.3 .5 .4 & asparagine synthetase & ASN1 & AT3G47340 & & -2.913 \\
\hline 6.3 .5 .4 & asparagine synthetase & ASN2 & AT5G65010 & & -0.486 \\
\hline 3.5 .1 .1 & asparaginase & & AT3G16150 & & -0.481 \\
\hline 2.6 .1 .1 & aspartate aminotransferase & ASP1 & AT2G30970 & & 0.582 \\
\hline 2.6.1.1 & aspartate aminotransferase & ASP2 & AT5G19550 & & 1.132 \\
\hline 2.6 .1 .1 & aspartate aminotransferase & ASP3 & AT5G11520 & & 0.709 \\
\hline 2.6 .1 .1 & aspartate aminotransferase & ASP4 & AT1G62800 & & 0.354 \\
\hline 2.6 .1 .2 & alanine:2-oxoglutarate aminotransferase & $\begin{array}{l}\text { AlaAT1 } \\
\text { AlaAT2 }\end{array}$ & $\begin{array}{l}\text { AT1G17290 } \\
\text { AT1G72330 }\end{array}$ & & 0.438 \\
\hline \multirow[t]{3}{*}{ 2.6.1.2/2.6.1.4 } & glutamate:glyoxylate aminotransferase & GGAT2 & AT1G70580 & & -0.680 \\
\hline & glycine decarboxylase complex $-\mathrm{H}$ protein & AtGDH3 & AT1G32470 & 0.593 & \\
\hline & glycine decarboxylase complex $-\mathrm{H}$ protein & AtGDH1 & AT2G35370 & 0.768 & \\
\hline 1.8.1.4 & glycine decarboxylase complex $-L$ protein & AtmLPD1 & AT3G17240 & & 0.689 \\
\hline 1.4 .4 .2 & glycine decarboxylase complex - P protein & AtGLDP1 & AT4G33010 & 0.439 & -1.126 \\
\hline 1.4 .4 .2 & glycine decarboxylase complex - P protein & AtGLDP2 & AT2G26080 & & -0.532 \\
\hline 2.1 .2 .10 & glycine decarboxylase complex - T protein & AtGDT1 & AT1G11860 & & -0.600 \\
\hline 2.1 .2 .1 & serine hydroxymethyltransferase & SHM1 & AT4G37930 & & -0.513 \\
\hline 2.1 .2 .1 & serine hydroxymethyltransferase & $\mathrm{SHM} 3$ & AT4G32520 & & 0.532 \\
\hline 2.1 .2 .1 & serine hydroxymethyltransferase & $\begin{array}{l}\text { SHM4 } \\
\text { SHM5 }\end{array}$ & $\begin{array}{l}\text { AT4G13930 } \\
\text { AT4G13890 }\end{array}$ & & 0.535 \\
\hline 4.1.1.15 & glutamate decarboxylase & $\begin{array}{l}\text { GAD3 } \\
\text { GAD4 }\end{array}$ & $\begin{array}{l}\text { AT2G02000 } \\
\text { AT2G02010 }\end{array}$ & & 1.441 \\
\hline 2.6.1.19 & $\gamma$-aminobutyric acid transaminase & GABA-T1 & AT3G22200 & & 0.720 \\
\hline 1.2 .1 .24 & succinic semialdehyde dehydrogensase & SSADH1 & AT1G79440 & & 0.516 \\
\hline 1.1.1.86 & ketolacid reductoisomerase & KARI & At3g58610 & & 0.380 \\
\hline 4.2.1.9 & dehydroxyacid dehydratase & DHAD & At3g23940 & & 0.857 \\
\hline 6.3 .2 .2 & glutamate-cysteine ligase & GSH1 & AT4G23100 & & 0.587 \\
\hline 6.3 .2 .3 & glutathione synthetase & GSH2 & AT5G27380 & & 0.855 \\
\hline 1.4 .1 .3 & glutamate dehydrogenase & $\mathrm{GDH} 2$ & AT5G07440 & & 1.126 \\
\hline 2.3 .1 .1 & $\mathrm{~N}$-acetyltransferase & NAGS & AT4G37670 & & 0.755 \\
\hline 6.3 .5 .5 & carbamoyl-phosphate synthase & CPS & AT3G27740 & & 0.696 \\
\hline 6.3 .5 .5 & carbamoyl-phosphate synthase & CPS & AT1G29900 & & 0.701 \\
\hline 2.1 .3 .3 & ornithine carbamoyltransferase & OTC & AT1G75330 & & 0.436 \\
\hline \multirow[t]{6}{*}{6.3 .4 .5} & arginosuccinate synthase & AS & AT4G24830 & & 0.596 \\
\hline & nitrate transporter & NRT1.1 & AT1G12110 & & 0.432 \\
\hline & nitrate transporter & NRT1.3/NTP3 & AT3G21670 & & -0.703 \\
\hline & nitrate transporter & NRT1.5 & AT1G32450 & & 0.382 \\
\hline & nitrate transporter & NRT1.7 & AT1G69870 & 0.501 & 1.760 \\
\hline & nitrate transporter & AtNRT2.7 & AT5G14570 & & 0.546 \\
\hline
\end{tabular}


Table 2: Genes that are involved in major glutamate-related pathways and that are differentially expressed between the glu1-2 mutant and the wild-type mutant (Continued)

\begin{tabular}{|c|c|c|c|c|}
\hline nitrate uptake & NRT3.1/NAR2.1 & AT5G50200 & & 0.939 \\
\hline nitrate/proton antiporter & AtClCa & AT5G40890 & & -0.689 \\
\hline ammonium transporter & AMT2.1 & AT2G38290 & & 1.495 \\
\hline vacuolar tonoplast intrinsic protein & AtTIP2;1 & AT3G16240 & & -0.554 \\
\hline vacuolar tonoplast intrinsic protein & AtTIP2;3 & AT5G47450 & -1.105 & \\
\hline amino acid permease & AAP1 & AT1G58360 & & -0.523 \\
\hline amino acid permease & AAP4 & AT5G63850 & -0.586 & -0.470 \\
\hline amino acid permease & AAP5 & AT1G44100 & & 0.901 \\
\hline amino acid permease & AAP6 & AT5G49630 & & -0.532 \\
\hline glutamate influx & LHT1 & AT5G40780 & -0.411 & \\
\hline glutamate receptor family protein & AtGLR1.4 & AT3G07520 & & -0.453 \\
\hline glutamate receptor family protein & AtGLR3.2 & AT4G35290 & & -0.613 \\
\hline glutamate receptor family protein & AtGLR3.7 & AT2G32400 & & 0.338 \\
\hline
\end{tabular}

List of genes encoding enzymes involved in $\mathrm{N}$-assimilation and glutamate biosynthesis and transformation described in the text, and whose expression is affected by knocking down Fd-GOGAT1 in the glu1-2 mutant. Most of the listed enzymes are also depicted in Figure 8 . The presence of two gene IDs in some boxes indicates a nondiscriminating probe, i.e. a probe recognising more than one transcript so that a change in expression can not be attributed to a specific gene.

given below, starting from the endpoint (i.e. glutamine and glutamate synthesis) and expanding to the steps leading up to glutamate, before focussing on the pathways that utilize glutamate in the production of other compounds. This is complemented by analysis of certain amino acid contents in the glu1-2 mutant.

\section{Changes in expression levels of genes encoding glutamate} synthases and glutamine synthetases

Comparison of expression levels in our microarray assays indicates that Fd-GOGAT1 (GLU1;At5g04140) is more highly expressed in leaves than in roots (signal intensity: $\log _{2}=10.84$ versus $\log _{2}=5.06 ; \Delta \log _{2}=5.78$ ) of 18 day old in vitro grown $A$. thaliana wild type plants (Col-0 ecotype) (Additional file 1). This is in accordance with earlier published results and gene expression data publicly available $[5,6,18,19]$. As expected, the expression of Fd-GOGAT1 (At5g04140) was downregulated in the glu1-2 mutant (Table 2). There was a $\log _{2}$ ratio of -5.74 between the expression levels of Fd-GOGAT1 in leaves of wild type and the mutant. In roots the difference was more moderate with a reduction in expression of $\log _{2}=$ -0.54 (only significant at $\mathrm{P}=0.05$ ). It should however be noted that residual levels of transcripts for Fd-GOGAT1 are still detectable on the microarrays from the glu1-2 mutant, and that these are similar in roots and leaves.

The gene GLU2 (At2g41220) encoding Fd-GOGAT2, the second $A$. thaliana $\mathrm{Fd}$-dependent glutamate synthase, is upregulated $\left(\log _{2}=1.07\right)$ in leaves but not affected in roots of the glu1-2 mutant. The NADHGOGAT (EC1.4.1.14) encoding gene At5g53460 is also slightly upregulated $\left(\log _{2}=0.71\right)$ in glu1-2 leaves but not affected in roots (Table 2 ). This could indicate a partial recovery of the loss of the plastid-localized
Fd-GOGAT1 by these enzymes in leaves as NADHGOGAT and Fd-GOGAT2 are localized to plastids. Fd-GOGAT2 has however higher expression levels in roots than in leaves and is therefore more likely involved in primary nitrogen assimilation in roots [5]. In addition, NADH-dependent glutamate synthase activity only makes up a small percentage of the total glutamate synthase activity in $A$. thaliana leaves and NADHdependent activity is not affected in Fd-GOGAT deficient mutants $[7,9]$. It should also be noted that posttranscriptional regulation has been hypothesised for Fd-GOGAT in tobacco and A. thaliana [20,21].

Glutamine is the substrate of GOGATs for the synthesis of glutamate (Figure 8) and glutamine synthetases (EC 6.3.1.2) catalyse the synthesis of glutamine from ammonium $\left(\mathrm{NH}_{4}^{+}\right)$using ATP. Of the five putative $A$. thaliana genes encoding the cytoplasmic glutamine synthetase 1 (GS1), two were upregulated (At5g37600/ GLN1.1 and At3g17820/GLN1.3) whereas one (At5g16570/GLN1.4) was slightly downregulated in glu12 leaves. The gene At $5 g 35630$ encoding glutamine synthetase 2 (GS2), which is dual-targeted to the plastid and mitochondria [22], was not affected. None of the genes encoding glutamine synthetases 1 or 2 were affected in the roots of the glu1-2 mutant.

Genes encoding enzymes involved in the primary nitrogen assimilation leading to the formation of glutamine and glutamate

Glutamine and glutamate play a central role in the primary assimilation of nitrogen (Figure 1). Hence, genes encoding enzymes catalysing the reactions leading to the formation of glutamine from nitrate are affected in the glu1-2 mutant (Table 2), mostly in leaves. 


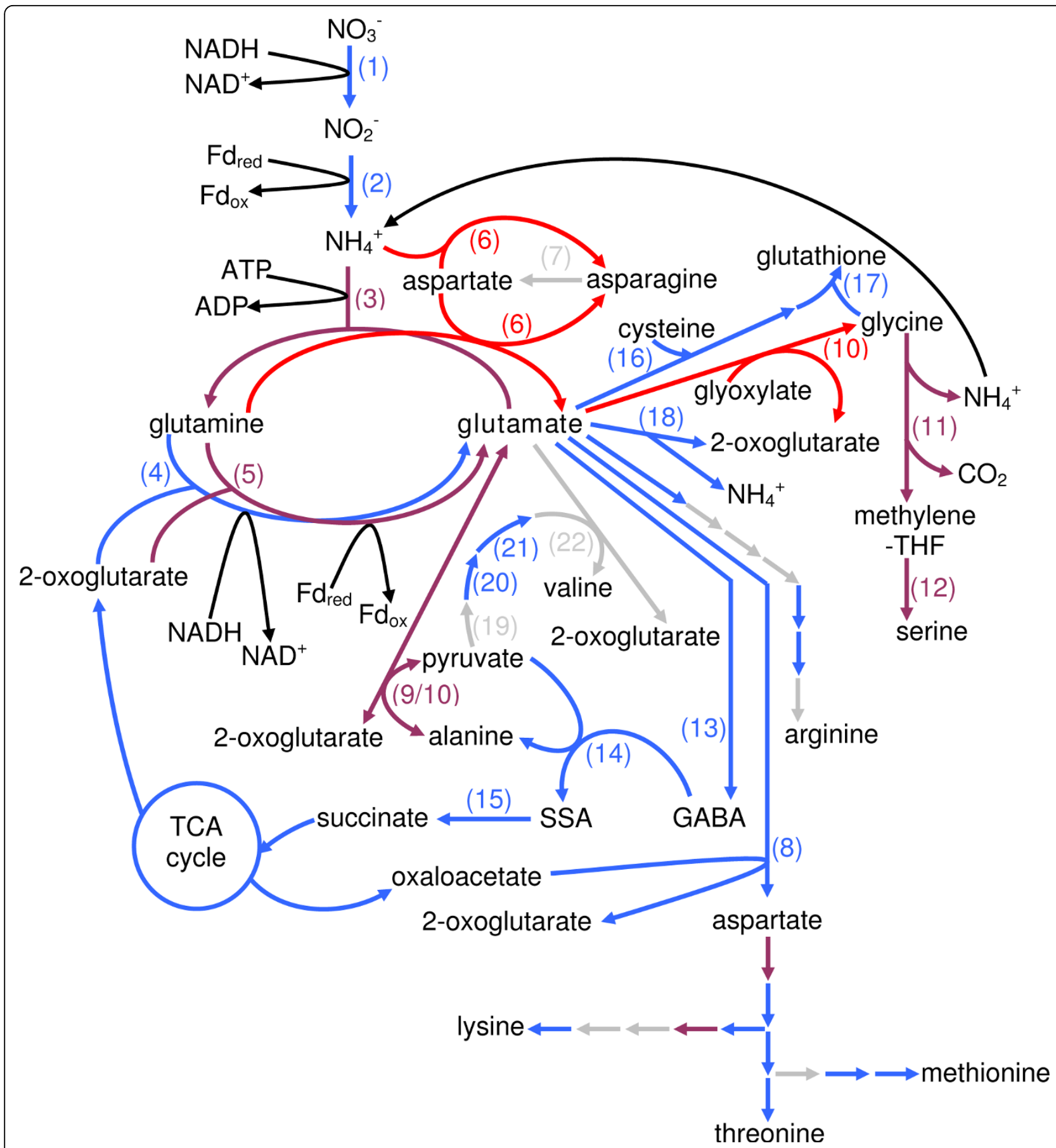

Figure 8 Primary nitrogen assimilation and glutamate metabolism. Simplified schematic representation of the pathways leading to the synthesis and the conversion of glutamate and the way they are affected in the glu1-2 mutant. Only the data related to glu1-2 leaves is depicted. Colour code: blue are upregulated, red are downregulated, violet are both up- and downregulated steps whereas grey are unaffected steps of these pathways. Enzymes: (1) nitrate reductase, (2) nitrite reductase, (3) glutamine synthetase, (4) NADH-GOGAT, (5) Fd-GOGAT, (6) asparagine synthase, (7) asparaginase, (8) aspartate aminotransferase, (9) alanine:2-oxoglutarate aminotransferase, (10) glutamate:glyoxylate aminotransferase, (11) glycine decarboxylase complex, (12) serine hydroxymethyltransferase, (13) glutamate decarboxylase, (14) $\gamma$-aminobutyric acid transaminase, (15) succinic semialdehyde dehydrogenase, (16) glutamate-cysteine ligase, (17) glutathione synthetase, (18) glutamate dehydrogenase, (19) acetohydroxyacid synthase, (20) ketolacid reductoisomerase, (21) dehydroxyacid dehydratase, (22) branched-chain aminotransferase. Subcellular compartmentalisation is not taken into account in this figure and reductants are only indicated for some of the reactions. The detailed data of the genes depicted in this figure and related data for genes affected in glu1-2 roots is presented in Table 2. 
Some of the genes encoding nitrate reductase (NADHNAR; EC 1.7.1.1) and nitrite reductase (NIR1; EC 1.7.7.1), are upregulated in glu1-2 leaves while unaffected in glu1-2 roots. These enzymes are responsible for the reduction of nitrate and nitrite respectively, leading to the formation of $\mathrm{NH}_{4}{ }^{+}$, which serves as substrate by glutamine synthetase. The upregulation of nitrate reductase expression levels was previously observed in tobacco plants deficient in Fd-GOGAT activity [23].

Glutamine and aspartate are used as substrates for the synthesis of glutamate and asparagine, in an ATPdependent reaction catalysed by asparagine synthase (ASN; EC 6.3.5.4)(for review: [24]). Of the three A. thaliana genes encoding asparagine synthases, two were downregulated in glu1-2 leaves but none was affected in roots (Table 2). ASN1 (At3g47340) is one of the ten most downregulated genes in the glu1-2 mutant leaves. It has been shown that $A S N 1$ is induced by dark and reduced by light (or sucrose) while $A S N 2$, which is moderately downregulated, is induced by light. These two genes also respond differently to asparagine, glutamine and glutamate with $A S N 1$ expression being induced and ASN2 expression being reduced ([24] and references therein). Overexpressing ASN1 leads to higher asparagine levels in seeds and phloem [25] and Masclaux-Daubresse et al. [21] have recently shown that asparagine synthase can also catalyse the formation of asparagine from aspartate using ammonium directly. None of the four genes encoding asparaginases (EC 3.5.1.1), which are responsible of degrading asparagine into aspartate, were affected in the leaves of the glu1-2 mutant (Figure 8 ). Hence, the reduced expression of asparagine synthase encoding genes in glu1-2 leaves could indicate lower levels of asparagine. In Fd-GOGAT deficient barley plants, the levels of asparagine are however higher than in wild-type plants [10].

\section{Multiple pathways leading to the transformation and degradation of glutamate are also affected}

Glutamate serves directly or indirectly as substrate in the production of a series of compounds, like amino acids, nucleic acids, ureides, and polyamines (Figure 1; [26]). Hence, reducing Fd-GOGAT1 expression could have a knock-on effect on the genes encoding enzymes implicated in these various biosynthetic pathways (Figure 8).

\section{Amino acid biosynthesis}

Aspartate aminotransferases (ASPs or AATs; EC 2.6.1.1) catalyse the transfer of the $\alpha$-amino group of glutamate to oxaloacetate to form aspartate and 2-oxoglutarate. In glu1-2 leaves, four of the five A. thaliana genes (putatively) encoding ASPs [26] are upregulated in glu1-2 leaves. Aspartate is a precursor of asparagine and the aspartate family of amino acids such as lysine, threonine and methionine (Figure 8). From the changes in expression levels of genes involved in these pathways the synthesis of these latter amino acids seems to be induced in glu1-2 leaves.

The transfer of the $\alpha$-amino group of glutamate to pyruvate to form alanine is catalysed by alanine aminotransferases (AlaAT or AOAT; EC 2.6.1.2) which comprise four members, subdivided into two groups, in $A$. thaliana [27]. The first group, composed of AlaAT1 and AlaAT2 that possess alanine aminotransferase activity, is slightly induced in leaves but not in roots of the glu1-2 mutant (Table 2). AlaAT1 has recently been suggested to catalyse the reverse reaction (i.e. conversion of alanine to pyruvate) [28], which could lead to a production of glutamate (Figure 8) to compensate for the lack of Fd-GOGAT1. Low levels of glutamate may shift this reaction equilibrium to favour glutamate production. The members of the second group, two peroxisomal enzymes, possess a glycine (or glutamate:glyoxylate) aminotransferase (GGAT) activity in addition to their alanine aminotransferase activity (Figure 8). Glyoxylate is thereby transaminated to glycine, accompanied by the consumption of glutamate and the production of 2-oxoglutarate, during photorespiration. Neither of these two genes is affected in glu1-2 roots (Table 2) but the expression of GGAT2 (At1g70580) is reduced in glu1-2 leaves. The further conversion of glycine to serine involves the glycine decarboxylase complex (GDC) and serine hydroxymethyltransferase (SHMT; EC 2.1.2.1). The glycine decarboxylase complex is composed of four mitochondrial proteins $(\mathrm{H}, \mathrm{L}, \mathrm{P}$ and $\mathrm{T})$ encoded by a total of eight genes in A. thaliana [29]. The genes encoding the two $\mathrm{P}$ proteins are both downregulated (Table 2). Knocking out these genes simultaneously provokes a lethal phenotype, also under nonphotorespiratory conditions, which points towards a role of GDC in other metabolic processes than photorespiration [30]. Of the seven $A$. thaliana genes putatively encoding serine hydroxymethyltransferases, four show a changed expression in glu1-2 leaves (Table 2). SHM1 (At4g37930) encoding the mitochondrial SHMT1 is downregulated. Interestingly, the knock-out mutant shm1-1 also displays a lethal photorespiratory phenotype [31] and a physical interaction between Fd-GOGAT1 and SHMT1 in mitochondria was recently established [8]. Three genes encoding putative cytosolic serine hydroxymethyltransferases were on the other hand almost equally upregulated in leaves. None of the SHMT-encoding genes was affected in glu1-2 roots (Table 2).

Arginine is formed from glutamate and glutamine in a multiple-reaction pathway [32] that shows a slight overall induction in glu1-2 mutant leaves (Figure 8; Table 2). 
This may be responsible for increased production of arginine that has been observed in Fd-GOGAT deficient plants and which may prevent excessive accumulation of glutamine [11]. In root tissue of the glu1-2 mutant none of the transcripts of these genes involved in arginine synthesis were affected.

Valine biosynthesis starts with the condensation of two molecules of pyruvate by acetohydroxyacid synthase (AHAS; EC 2.2.1.6), also known as acetolactate synthase [33]. Neither the gene At3g 48560 encoding the catalytic subunit, nor the genes At2g31810 and At5g16290 encoding the regulatory subunit, are significantly affected in the glu1-2 mutant (Figure 8 ). The resulting 2-acetolactate is converted to 2,3-dihydroxy-3-isovalerate by ketolacid reductoisomerase (KARI; EC 1.1.1.86) and its gene At3g58610 is slightly upregulated in glu1-2 leaves. The gene At3g23940 encoding dehydroxyacid dehydratase (DHAD; EC 4.2.1.9), which catalyses the conversion of 2,3-dihydroxy-3-isovalerate to $\alpha$-ketoisovalerate, is also induced in glu1-2 leaves. Branched-chain aminotransferases (BCAT; EC 2.6.1.42) catalyse the subsequent and last step in the synthesis of valine from $\alpha$-ketoisovalerate, which is accompanied by the conversion of glutamate to 2-oxoglutarate. However none of the BCATencoding genes (At1g10070, At3g49680 and At5g65780) implicated in this step is affected in the glu1-2 mutant. Hence, a few of the genes encoding biosynthetic enzymes involved in valine biosynthesis are induced, indicating possibly a slight activation of the valine biosynthetic pathway.

\section{Glutathione biosynthesis}

Glutamate is used for the synthesis of glutathione in a two-reaction pathway (Figure 8) catalysed by glutamatecysteine ligase (GSH1; EC 6.3.2.2) and glutathione synthetase (GSH2; EC 6.3.2.3). Both GSH1 (At4g23100) and GSH2 (At5g27380) are upregulated in glu1-2 mutant leaves (Table 2). Mutants deficient in GSH1 have been shown to contain lower levels of glutathione and are more sensitive to stresses. Complete knock-out of GSH1 leads to an embryo-lethal phenotype [34]. Upregulation of glutathione biosynthetic genes in glu1-2 may be connected to the upregulation of numerous glutathione S-transferases (see later).

\section{Gamma-aminobutyrate and succinate synthesis}

Under certain conditions glutamate may be converted to gamma-aminobutyrate (GABA) in a cytosolic reaction catalysed by glutamate decarboxylase (GAD; EC 4.1.1.15). The two GAD-encoding genes GAD1 (At5g17330) and GAD2 (At1g65960) initially identified in A. thaliana $[35,36]$ are not affected in the leaves or roots of the glu1-2 mutant. Of the three additional genes encoding putative GADs that have recently been identified based on homology [37], GAD3 and/or GAD4 (undifferentiating probe) were upregulated in glu1-2 mutant leaves (Table 2). The gene encoding GABA-T1 (EC 2.6.1.19; At3g22200), the $\gamma$-aminobutyric acid transaminase that catalyses the conversion of GABA into succinic semialdehyde (SSA), simultaneously producing alanine from pyruvate, is also induced in leaves. The conversion of SSA to succinate by succinic semialdehyde dehydrogensase (SSADH) is also upregulated in glu1-2 leaves (Table 2).

\section{Glutamate catabolism}

Glutamate is catabolised into oxoglutarate and ammonium by glutamate dehydrogenase (GDH; EC 1.4.1.2) (Figure 8), a mitochondrial enzyme that exists under the form of homo- or heterohexamers of two subunits in $A$. thaliana [38]. Only GDH2 (At5g07440), encoding the $\beta$ subunit, is affected in the glu1-2 mutant, showing surprisingly an increased expression in mutant leaves (Table 2). Although the role of glutamate dehydrogenase in glutamate metabolism has remained controversial for a long time, recent evidence indicates that GDHs are indeed responsible for the deamination of glutamate leading to the formation of ammonium and 2-oxoglutarate [21,39]. Induction of GDH2 expression could hence lead to a further depletion of the pool of glutamate in the glu1-2 mutant but would simultaneously increase the levels of oxoglutarate to fuel the TCA cycle. Although the physiological role of GDH is currently still unclear, there seems to be a consensus that GDH is not essential for primary nitrogen assimilation. Instead a role of GDH in the breakdown of several amino acids into their corresponding keto-acids under carbon deficiency was proposed [39]. The the $\alpha$ - and $\beta$-subunit composition of glutamate dehydrogenase hexamers may also influence its activity and hence its physiological role [40]. Lancien et al. [41] proposed that ammonium and glutamine would favour the amination reaction. In tobacco plants with reduced Fd-GOGAT activity the aminating, but not the deaminating activity, of glutamate dehydrogenase was indeed reported [42].

\section{Cellular uptake of glutamate}

Amino acids can be exported from their site of synthesis and transported via the vascular tissue to newly developed tissues. In A. thaliana, glutamate is one of the predominant amino acids found in the phloem sap and xylem exudates [18]. Members of the A. thaliana amino acid permease (AAP) family have been shown to catalyse the low affinity influx of a broad range of amino acids, including glutamate [43]. Of these, AAP1 (At1g58360), AAP4 (At5g63850) and AAP6 (At5g49630) were moderately downregulated, whereas AAP5 (At1g44100) was induced in glu1-2 leaves (Additional 
file 1). AAP1 has recently been shown to be involved in glutamate uptake into root cells and may have a role in the efficient use of nitrogen resources in the rhizosphere [44], but its expression was not affected in glu1-2 roots. Only AAP4 (At5g63850) was affected in roots, with a lower expression in the mutant than in the wild-type.

The related LHT1 (At5g40780) gene which appears to encode a high-affinity glutamate influx system [45] was also moderately downregulated in glu1-2 roots but not affected in glu1-2 leaves. A role for LHT1 in root uptake of certain amino acids was also recently proposed, but its role in glutamate uptake may be limited as this was not affected in an lht1 mutant [46].

The gene At2g01170 encoding the recently identified bidirectional amino acid transporter BAT1 capable of import and export of glutamate and potentially involved in amino acid export from phloem to sink tissue [47] is moderately induced in glu1-2 leaves and not affected in roots.

\section{Changes in expression levels og genes involved in the synthesis of 2-oxoglutarate and the TCA cycle}

The synthesis of glutamate by NADH- and Fd-GOGATs necessitates 2-oxoglutarate, which is thus situated at the interface between $\mathrm{C}$ and $\mathrm{N}$ metabolism. As it is possible to affect the glutamate pool by feeding 2-oxoglutarate to plants, the supply of 2-oxoglutarate may be a key regulator of glutamate levels [48].

2-oxoglutarate is produced through the TCA cycle (for review: [41]) and several genes involved in the TCA cycle were upregulated in glu1-2 leaves (Figure 8; Additional file 5). These include genes encoding citrate synthase (CSY; EC2.3.3.1), succinate dehydrogenases (SDH; EC 1.3.5.1) and succinyl-CoA ligase (EC 6.2.1.4). Three of the five genes encoding NAD-dependent isocitrate dehydrogenase (IDH; EC 1.1.1.41) subunits are also upregulated in glu1-2 mutant leaves (Figure 8; Additional file 5). This increase in IDH transcript levels in the glu1-2 mutant is in contrast to the situation observed in tobacco plants with reduced FdGOGAT activity, where no change in transcript levels was observed. These tobacco plants did however show increased isocitrate dehydrogenase activity [42]. Recently, Lemaitre et al. [49] have shown that mutants lacking one of the three IDH subunits mentioned above do not exhibit changed levels in 2-oxoglutarate, glutamine and glutamate. The glu1-2 mutant leaves also showed an increase in the expression of four genes encoding putative components (EC 2.3.1.61 and EC 1.2.4.2) of the 2-oxoglutarate dehydrogenase system. On the other hand, the genes At2g47510/ At5g50950 encoding fumarate hydratases (FUM; EC
4.2.1.2) were downregulated in glu1-2 leaves. Interestingly, none of the TCA cycle-implicated genes mentioned above were significantly affected in glu1-2 roots. These data indicate an overall induction of the TCA cycle in glu1-2 leaves potentially leading to an increase in 2-oxoglutarate production. Higher levels of 2-oxoglutarate have been observed in Fd-GOGAT deficient tobacco plants [11].

2-oxoglutarate can also be synthesised in the cytosol by export of citrate from mitochondria and the subsequent action of aconitases and isocitrate dehydrogenases. Two aconitase-encoding genes (ACO; EC 4.1.2.3) and two genes putatively encoding cytosolic NADP-dependent isocitrate dehydrogenases (IDCH; EC 1.1.1.42) are upregulated in glu1-2 leaves (Additional file 5). Although this could indicate an increase in cytosolic 2-oxoglutarate synthesis, it should however be noted that a role of the latter in cytosolic 2-oxoglutarate production has not yet been established.

\section{Uptake, transport and distribution of nitrate and ammonium}

Fd-GOGAT1 is a key enzyme in the primary assimilation of nitrogen and knocking it down was expected to change the transcriptional level of genes involved in nitrogen uptake and transport (Table 2).

The NRT1 and NRT2 nitrate transporter families [50] were however only marginally affected. Of the 53 genes that encode putative NRT1 nitrate transporters in $A$. thaliana, five were induced in glu1-2 leaves. Of these, NRT1.1 (At1g12110) has been implicated in stomatal aperture and drought stress [51] and its $\mathrm{NO}^{-}$sensing role in root architecture was recently described [52]. NRT1.5 (At1g32450) and NRT 1.7 (At1g69870) are less well characterised but have been shown to transport nitrate in a heterologous system [50]. The latter of these genes is also slightly induced in glu1-2 roots. On the other hand, eight genes encoding putative NRT1 family members, such as the NRT1.3/NTP3 (At3g21670; [53]), are downregulated in glu1-2 leaves. Out of the seven NRT2-encoding genes, only At5g14570 (NRT2.7) was moderately induced in glu1-2 leaves (Table 2).

An essential role in nitrate uptake has also recently been shown for the NAR2-like protein $[54,55]$. The gene NRT3.1/NAR2.1 (At5g50200) encoding this protein is induced in glu1-2 leaves (Table 2). None of the genes implicated in nitrate uptake and transport mentioned above was affected in glu1-2 roots.

The ammonium transporter (AMT) proteins, which are encoded by six genes in A. thaliana, are likely responsible for high affinity ammonium transport in plant roots [56]. The gene At2g38290 encoding the ammonium 
transporter AMT2;1 was upregulated in glu1-2 leaves (Table 2), but its contribution to ammonium uptake in planta has been questioned recently [57].

The nitrate/proton antiporter AtCLCa mediates nitrate accumulation in vacuoles $[58,59]$ and its encoding gene At5g40890 is down-regulated in glu1-2 leaves (Table 2). Several NRT1 gene-encoding proteins are claimed to be involved in nitrate distribution in different cellular compartments and tissues, but detailed evidence has not been provided yet [50].

Two vacuolar tonoplast intrinsic proteins (AtTIP2;1 and AtTIP2;3) have been proposed to be responsible for $\mathrm{NH}_{3}$ transport across the tonoplast membrane in $A$. thaliana [60]. AtTIP2;1 (At3g16240) is downregulated in glu1-2 leaves, whereas AtTIP2;3 (At5g47450) is downregulated in glu1-2 roots (Table 2).

\section{NMR analysis of glu1-2 mutant leaves and roots reveal differences in amino acid contents}

Although the Fd-GOGAT deficient gluS/gls mutants did not seem to be impaired in primary nitrogen assimilation [9], it was later shown that Fd-GOGAT1/GLU1 indeed plays a role in primary nitrogen metabolism [5]. As described above, knocking down Fd-GOGAT1 in the glu1-2 mutant affected several genes involved in primary nitrogen assimilation but the effects at the transcriptional level were more moderate than expected. Metabolite analysis by NMR spectroscopy of glu1-2 mutant tissue was performed to assess metabolic changes in the mutant.

Using this technique, the four amino acids alanine, threonine, valine and glutamine were identified and some changes in their levels in the glu1-2 mutant were revealed (Table 3; Figure 9). Most importantly glutamine contents were increased more than eight-fold in glu1-2 leaves and more than two-fold in glu1-2 roots. This indicates that the loss of Fd-GOGAT1 is not compensated by Fd-GOGAT2 or NADH-GOGAT activity in the glu1-2 mutant. The fact that the latter two enzymes are more active in roots than in leaves [7] is consistent with

Table 3 Contents of some amino acids in wild type and glu1-2 plants

\begin{tabular}{llllll}
\hline & & glutamine & valine & alanine & threonine \\
\hline Leaves & wild type & $5.07 \pm 0.91$ & $0.21 \pm$ & $1.15 \pm$ & $0.64 \pm$ \\
& & 0.04 & 0.18 & 0.07 \\
\hline \multirow{2}{*}{ glu1-2 } & $42.90 \pm$ & $0.39 \pm$ & $0.76 \pm$ & $0.42 \pm$ \\
& mutant & 5.42 & 0.09 & 0.19 & 0.09 \\
\hline roots & wild type & $6.48 \pm 1.51$ & $0.33 \pm$ & $0.61 \pm$ & $1.16 \pm$ \\
& & & 0.05 & 0.03 & 0.09 \\
\hline & glu1-2 & $15.08 \pm$ & n.i. & $0.93 \pm$ & $1.26 \pm$ \\
& mutant & 2.71 & & 0.16 & 0.17 \\
\hline
\end{tabular}

Glutamine, valine, alanine and threonine contents in glu1-2 and wild type leaves and roots measured by NMR spectroscopy. Values are expressed in $\mu$ mol.g ${ }^{-1}$ fresh weight \pm standard deviation $(n=4)$. n.i. = not integrated due to overlapping resonances a smaller increase in glutamine levels in glu1-2 roots than in leaves. Higher glutamine contents have been previously described for Fd-GOGAT deficient plants of A. thaliana, barley and tobacco [9-11,61]. Principal component analysis (PCA) of the NMR spectra indicates that glutamine is to a large extent responsible of the changes detected between the wild-type and the glu1-2 mutant (Figure 9A, left panel). PC1 explains 79\% of the total explained variance in leaf samples and allows to discriminate between $g l u 1-2$ and wild-type leaf samples (Figure 9A, right panel). Conversely to the increase in glutamine, the levels of glutamate are expected to be reduced in the glu1-2 mutant. Reduced levels of glutamate have been described for Fd-GOGAT deficient barley and $A$. thaliana plants $[10,61,62]$. The levels of valine were also considerably increased in glu1-2 leaves, consistent with previous reports on Fd-GOGAT deficient tobacco plants ([11]; Figure 9B). This is however difficult to explain by the transcriptional profiling of the glu1-2 mutant. Indeed, only two genes of the valine biosynthetic pathway are slightly upregulated (Figure 8; Table 2) and genes involved in the degradation of valine are not affected. In addition, the diversion of this pathway towards leucine biosynthesis via the use of $\alpha$-ketoisovalerate seems rather upregulated than downregulated (data not shown). Alanine content was reduced in glu12 leaves and increased in glu1-2 roots, although the changes were more moderate (Figure 9B). This could be related to the decrease in glutamate levels and increased reverse alanine:2-oxoglutarate aminotransferase activity, i.e. the conversion of alanine to pyruvate (Figure 8). Reduced foliar levels of alanine have previously been observed in Fd-GOGAT deficient barley and tobacco plants $[11,61]$. Threonine levels were only affected in glu1-2 leaves, showing a slight reduction (Figure 9B). In Fd-GOGAT deficient tobacco plants the levels of foliar alanine and threonine were respectively reduced and unaffected [11]. The reduced levels of alanine and threonine in glu1-2 leaves are accompanied by an overall upregulation in gene expression in the biosynthetic pathways of these amino acids (Figure 8). Other amino acids were not identified by NMR, but changes in several amino acids have been previously reported in Fd-GOGAT deficient plants [10,11].

Analysis with PathExpress identified starch and sucrose metabolism as being downregulated in leaves and roots of the glu1-2 mutant (see above). This is not surprising considering the close interaction between $\mathrm{C}$ and $\mathrm{N}$ metabolism through the GS/GOGAT cycle. Differences in the contents of sucrose and glucose were not observed by NMR spectroscopy of glu1-2 leaves and roots (data not shown). This is consistent with results from tobacco plants with reduced Fd-GOGAT activity [42]. 

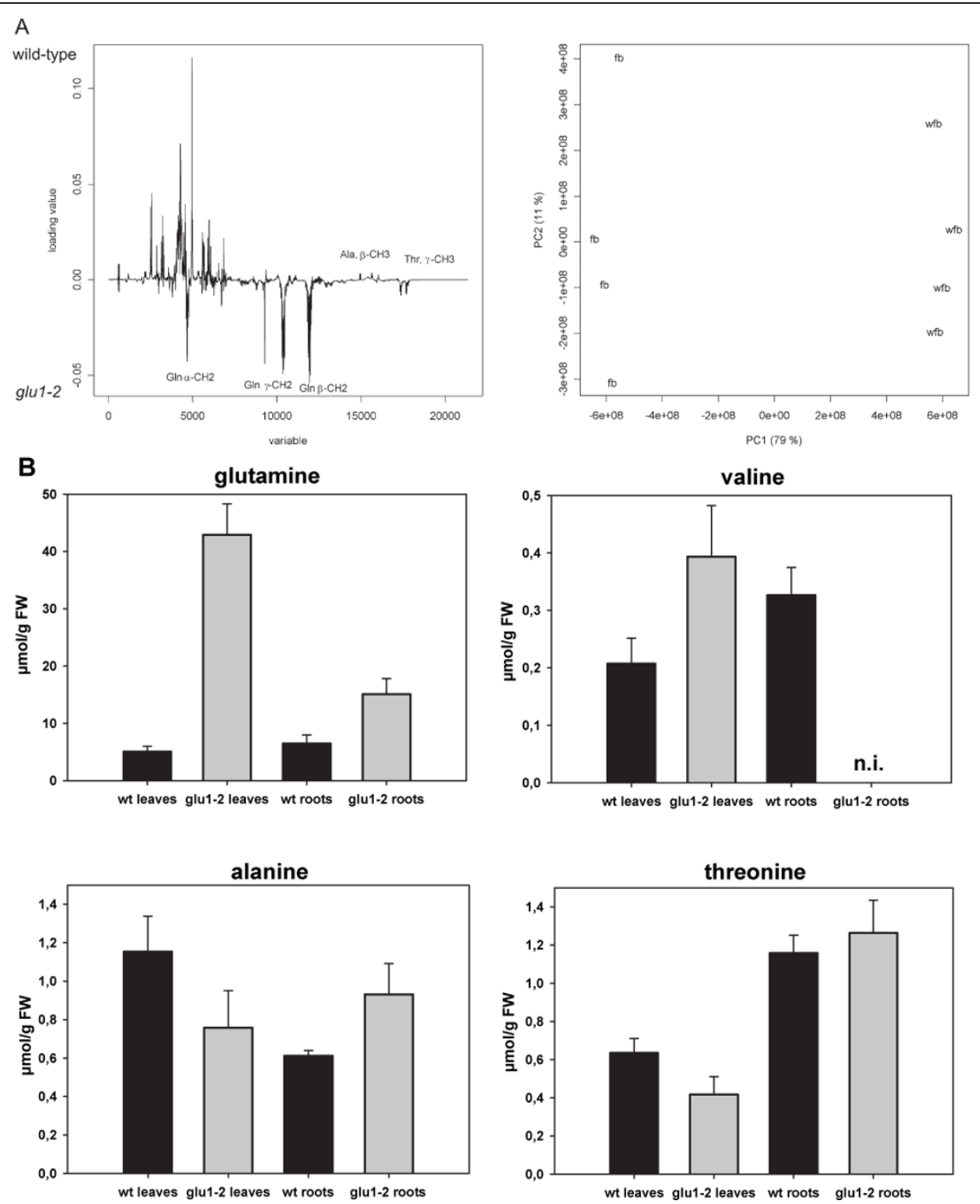

Figure 9 Analysis of metabolic changes in the glu 1-2 mutant by NMR spectroscopy. Metabolic changes in leaves and roots of mutant (glu1-2) and wild-type (wt) plants were analysed by NMR spectroscopy. (A) The loading plot (left) for PC1 from the PCA analysis of leaves show the resonances that are different between the wild type and mutant groups $(n=4)$. Scatter plot (right) of glu $1-2$ mutant $(\mathrm{fb})$ and wild-type $(\mathrm{wfb})$ leaf samples. (B) The contents of glutamine, valine, alanine and threonine are given in $\mu \mathrm{mol} / \mathrm{g}$ fresh weight $\pm S D(n=4)$. Values for valine in glu1-2 roots could not be integrated (n.i.) due to overlapping resonances.

\section{Secondary responses of the glu1-2 mutant revealed by transcriptional profiling \\ Photosynthesis and related biochemical processes are affected in glu 1-2 mutant leaves}

Photosynthesis and related biochemical processes were recurrently identified in our unbiased search of affected pathways (Additional files 2, 3 and 4). Especially the GO term GO:0015979 (photosynthesis), and to a lesser extent GO:0019684, GO:0042548 and GO:0042549, was revealed by GOstat as being affected in several of our datasets (Additional file 2). If only the GO terms related to photosynthesis that were identified by GOstat as being affected are taken into consideration, 37 genes show different expression levels in glu1-2 leaves (Additional file 6). All but one of these are repressed and the level of repression varies from $\log _{2}=-0.32$ to -1.76. Although the TAIR database to some extent categorises different genes into these GO terms, these are also almost exclusively downregulated (Additional file 6). If all genes included in GO:0015979 and its 


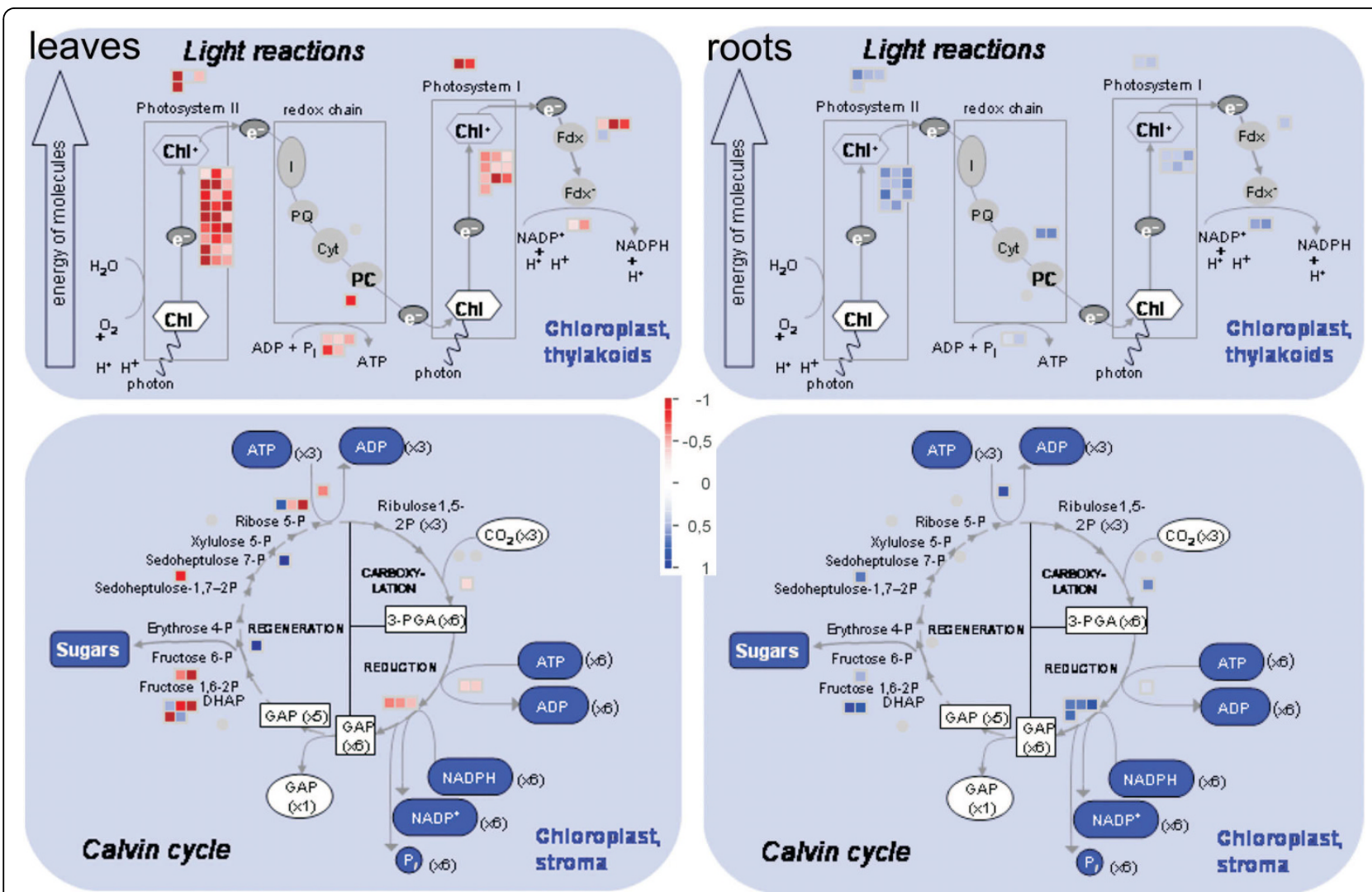

Figure 10 Changes in gene expression in photosynthesis-related pathways of the glu1-2 mutant. Expression changes of genes involved in photosynthesis in glu1-2 mutant leaves (left) and roots (right) using the MapMan software. Represented are only the genes showing a significant $(P=0.01)$ change in expression between the glu1-2 mutant and the wild-type and that have been attributed to the respective bins by MapMan. Genes whose expression is increased or decreased in the glu1-2 mutant tissue versus the corresponding wild-type tissue are shown by an increasingly intense blue and red colour, respectively. The graduation can be seen on the scale that is represented in the centre of the figure.

subcategories as provided by AmiGO are taken into condiseration, the list contains 49 unique genes not identified by GOstat whose expression is affected in the glu1-2 mutant leaves. Of these only five genes are (moderately) upregulated. The photosynthesis related bins of the MapMan software (Figures 4 and 10) identify another 71 genes with changed expression in glu1-2 leaves. All but ten of these are downregulated (Additional file 6). Hence, a total of more than 150 genes attributed to photosynthesis related pathways are affected in glu1-2 leaves, of which approximately $90 \%$ are downregulated. In glu1-2 roots, 52 genes attributed to the photosynthesis related GO terms or bins show a differential expression and these are exclusively induced (Additional file 6).

Several genes involved in the Calvin cycle are thus affected in the glu1-2 mutant, with most of them being downregulated in leaves and upregulated in roots (Figure 10). The most downregulated gene in the Calvin cycle in glu1-2 leaves is encoding a putative fructosebiphosphate aldolase (At4g26530).
A process directly linked to photosynthesis and the Calvin cycle is photorespiration, a consequence of the oxygenation of ribulose-1,5-biphosphate (RuBP) by RuBP carboxylase/oxygenase [3]. This oxygenation produces 3-phosphoglycerate and 2-phosphoglycolate, the latter being recycled into 3-phosphoglycerate by the photorespiratory cycle. In this process $\mathrm{O}_{2}$ is consumed in the plastid and $\mathrm{CO}_{2}$ and ammonium are released in the mitochondria. The released ammonium is reassimilated by the GS/GOGAT pathway in the plastid (for review: [63]). The essential role that glutamate synthase plays in this process is evidenced by the fact that mutants deficient in Fd-GOGAT activity exhibit a photorespiratory-dependent lethal phenotype $[5,9]$. Transcriptional profiling of the glu1-2 mutant indeed shows that genes involved in most of the steps of the photorespiratory cycle are downregulated in leaves (Figure 11; Table 4). These include the genes encoding phosphoglycolate phosphatase (PGLP1; At5g36700) and glycerate kinase (GLYK; At1g80380) of plastids and mitochondrial serine hydroxymethyltransferase (SHM1; 


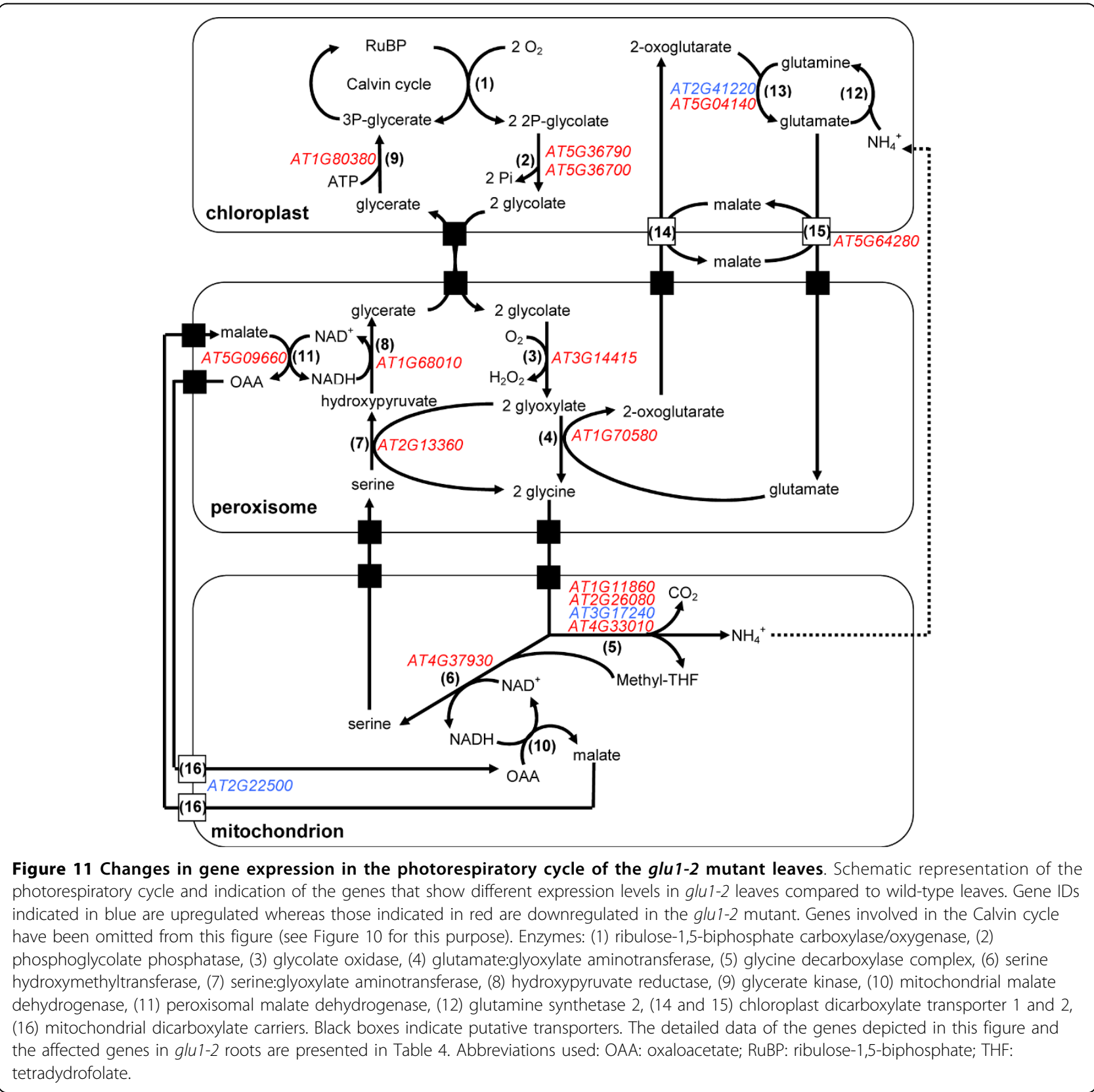

At4g37930). Knock-out mutants of these genes exhibit a conditional lethal photorespiratory phenotype [31,64,65]. The gene At1g68010 encoding the peroxisomal NADHdependent hydroxypyruvate reductase HPR1 is downregulated in glu1-2 leaves with no concomitant change of At1g79870 encoding the cytosolic isoform HPR2 that provides a cytosolic bypass to the photorespiratory cycle [66]. The gene encoding the dicarboxylate transporter DiT2.2 is also repressed in glu1-2 leaves. Its role is yet unclear, although the homolog DiT2.1 has been identified as a glutamate/malate translocator with an essential role in photorespiration [67]. A notable exception to the general downregulation of photorespiration-related genes is At $2 g 22500$ encoding one of the three recently characterised mitochondrial dicarboxylate carriers (DIC1-3) that are able to transport malate and oxaloacetate among other substrates [68]. In glu1-2 roots the expression of a smaller number of genes involved in photorespiration is affected by the glu1-2 mutation, and all these are upregulated (Table 4). It should also be noted that the changes in expression levels for both leaves and roots are moderate, which may explain the fact that our glu1-2 mutant has a less severe photorespiratory phenotype than the Fd-GOGAT1 mutants 
Table 4 Genes that are involved in the photorespiratory pathway and that are differentially expressed between the glu 1-2 mutant and the wild-type mutant

\begin{tabular}{|c|c|c|c|c|c|}
\hline EC \# & Enzyme/protein & Abbreviation & Gene ID & $\log _{2}$ root & $\log _{2}$ leaf \\
\hline 3.1.3.18 & phosphoglycolate phosphatase & $\begin{array}{l}\text { putative PGLP } \\
\text { AtPGLP1 }\end{array}$ & $\begin{array}{l}\text { AT5G36790 } \\
\text { AT5G36700 }\end{array}$ & 0.674 & -0.658 \\
\hline 1.1.3.15 & glycolate oxidase & GOX & $\begin{array}{l}\text { AT3G14415 } \\
\text { AT3G14420 }\end{array}$ & 0.655 & -0.464 \\
\hline \multirow[t]{3}{*}{$2.6 .1 .2 / 2.6 .1 .4$} & glutamate:glyoxylate aminotransferase & GGAT2 & AT1G70580 & & -0.680 \\
\hline & glycine decarboxylase complex - H protein & AtGDH3 & AT1G32470 & 0.593 & \\
\hline & glycine decarboxylase complex - H protein & AtGDH1 & AT2G35370 & 0.768 & \\
\hline 1.8 .1 .4 & glycine decarboxylase complex - L protein & AtmLPD1 & AT3G17240 & & 0.689 \\
\hline 1.4 .4 .2 & glycine decarboxylase complex - P protein & AtGLDP1 & AT4G33010 & 0.439 & -1.126 \\
\hline 1.4 .4 .2 & glycine decarboxylase complex - P protein & AtGLDP2 & AT2G26080 & & -0.532 \\
\hline 2.1 .2 .10 & glycine decarboxylase complex - T protein & AtGDT1 & AT1G11860 & & -0.600 \\
\hline 2.1 .2 .1 & serine hydroxymethyltransferase & SHM1 & AT4G37930 & & -0.513 \\
\hline 2.6 .1 .45 & serine:glyoxylate aminotransferase & AtSGT & AT2G13360 & & -0.566 \\
\hline 1.1 .1 .29 & peroxisomal hydroxypyruvate reductase & HPR1 & AT1G68010 & 0.705 & -0.689 \\
\hline 2.7 .1 .31 & glycerate kinase & GLYK & AT1G80380 & & -0.554 \\
\hline 1.1 .1 .37 & glyoxysomal malate dehydrogenase & $\begin{array}{l}\text { MDHG1/ } \\
\mathrm{pMDH} 2\end{array}$ & AT5G09660 & & -0.851 \\
\hline 1.4.1.7 & Fd-dependent glutamate synthase & Fd-GOGAT 1/GLU1 & AT5G04140 & & -5.738 \\
\hline \multirow[t]{3}{*}{ 1.4.1.7 } & Fd-dependent glutamate synthase & Fd-GOGAT 2/GLU2 & AT2G41220 & & 1.070 \\
\hline & $\begin{array}{l}\text { chloroplast } \\
\text { dicarboxylate transporter }\end{array}$ & DiT2.2 & AT5G64280 & & -0.439 \\
\hline & mitochondrial dicarboxylate transporter & $\mathrm{DIC1}$ & AT2G22500 & & 0.702 \\
\hline
\end{tabular}

List of genes encoding enzymes involved in the photorespiratory pathway and whose expression is affected by knocking down Fd-GOGAT1 in the glu1-2 mutant. See also Figure 11. The presence of two gene IDs in some boxes indicates a nondiscriminating probe, i.e. the change in expression can not be attributed to a specific gene.

characterised previously $[5,9]$. In addition, Takahashi et al. [69] showed that mutants impaired in photorespiration have accelerated photoinhibition of the photosystem II and that this is due to a suppressed repair process through inhibition of the D1 protein translation.

Due to the dual-targeting of glutamine synthetase 2 (GS2) to the plastid and mitochondria [22], other schemes of the reassimilation of ammonium than the photorespiration cycle depicted (Figure 11) and discussed here, have been proposed [2].

Chlorophyll is synthesised from glutamate. Many of the reactions of the chlorophyll biosynthetic pathway are downregulated (Figure 12), although the fold changes in expression are moderate (Additional file 6). However, two genes (At1g03630 and At5g54190) encoding protochlorophyllide reductases that catalyse the last step leading to the synthesis of chlorophyllide $a$ (Figure 12), show a more pronounced downregulation. Downregulation of genes implicated in chlorophyll biosynthesis and other photosynthesis related pathways, such as photorespiration (discussed above), in glu1-2 mutant leaves are consistent with its chlorotic phenotype (Figure 2). A chlorotic phenotype has been observed and reduced total chlorophyll contents have been measured in Fd-GOGAT deficient plants of $A$. thaliana, tobacco and barley $[5,9,11,61]$. Barley plants with reduced Fd-GOGAT activity have also been shown to have a reduced chlorophyll $a / b$ ratio [61]. Takahashi et al. [69] hypothesised that depletion of glutamate in the Fd-GOGAT mutant may lead to accumulation of glyoxylate that may be involved in a decline of the photosynthetic rate.

\section{The glu1-2 mutant displays a multiple stress response}

Categorisation of genes affected in leaves and roots of the glu1-2 mutant presented above showed a high number of genes related to stimulus and stress responses. More detailed analysis of the affected genes revealed that these changes in expression can not be attributed to one particular stress. Indeed, genes responsive to a multitude of different abiotic stresses, including light, drought, salt, heat and cold, oxidative stress and osmotic stress were affected (Additional file 2). This indicates that knocking down $F d$-GOGAT1 leads to a secondary response that consists in the activation of multiple stress responses or the activation of mechanisms that are common to several stresses. Due to the extensive nature of these transcriptional responses, only a selection will be presented briefly in the following section and the reader 


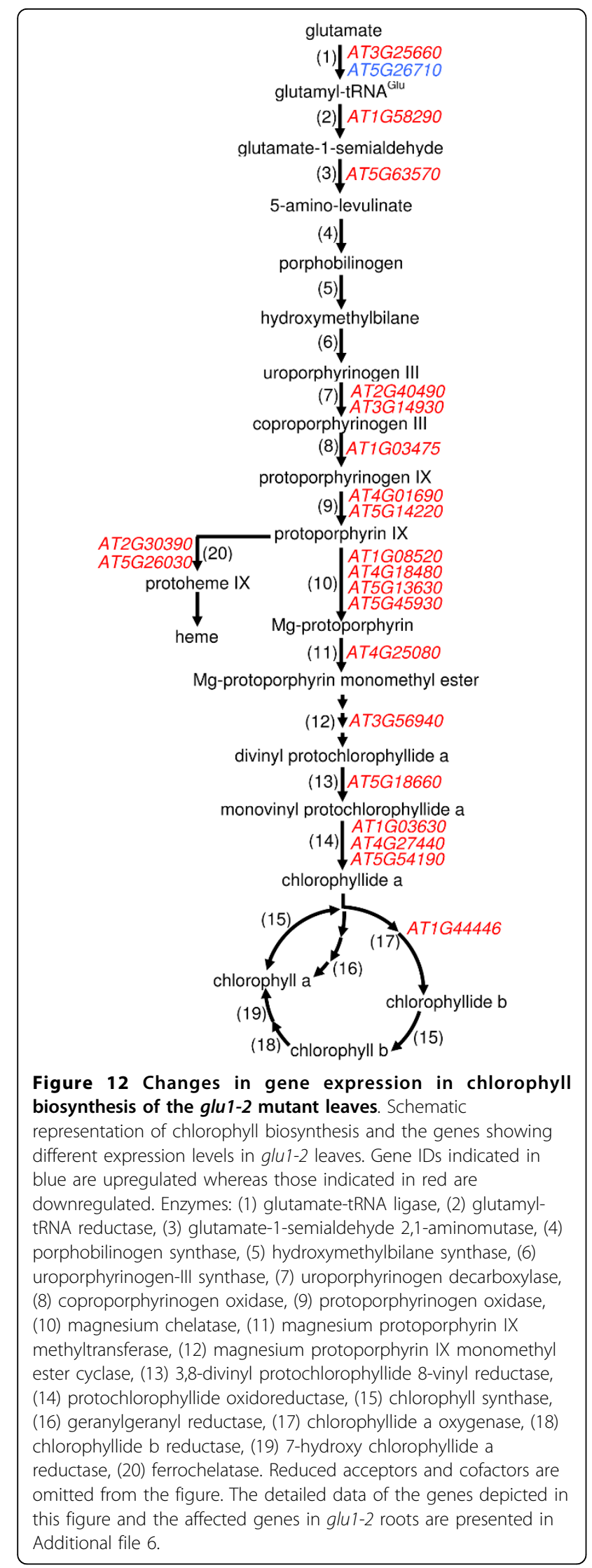

is kindly referred to Additional files 7 to 14 for the details on the affected genes.

Key stress responsive transcription factors affected in the glu1-2 mutant Numerous genes (putatively) encoding transcription factors belonging to different families, such as the zinc finger proteins (WRKY, $\mathrm{C} 2 \mathrm{H} 2, \mathrm{CCCH}$ ), MYBs and bHLHs (Additional file 7), were affected in the glu1-2 mutant.

WRKY25, whose encoding gene At2g30250 showed the highest induction of WRKY transcription factors in glu1-2 leaves, has been implicated in the defence against Pseudomonas syringae [70]. WRKY25 expression has also been shown to be induced in response to heat shock, wounding and oxidate stress. Higher levels of WRKY25 transcripts were detected in cytosolic ascorbate peroxidase Apx1-deficient plants, which maintain a high steady state level of $\mathrm{H}_{2} \mathrm{O}_{2}$ and activate ROS defence mechanisms [71].

The C2H2-type zinc finger transcription factor ZAT12 plays an important role in oxidative and abiotic stress response [71-73] and its encoding gene At5g59820, is upregulated in glu1-2 mutant leaves. ZAT12 expression is, like WRKY25, induced by heat shock, wounding and oxidate stress and higher transcripts were also detected in cytosolic ascorbate peroxidase (Apx1)-deficient plants [71]. ZAT12 expressing plants can tolerate oxidate stress [71] and show an increased freezing tolerance [73].

The genes encoding the two MYB-related transcription factors LHY (At1g01060) and CCA1 (At2g46830), which are associated with the circadian clock and act as negative regulators of the periodic flowering pathway [74], were strongly downregulated in glu1-2 leaves respectively. A role of LHY and CCA1 in the response to abiotic stresses has also been proposed [75].

Five genes (putatively) encoding bHLH transcription factors were among the $5 \%$ most repressed genes in glu1-2 leaves. While a role for BHLH101 (At5g04150) has not been described yet, it is phylogenetically closely linked to BHLHO39 (At3g56980; [76]) which is also strongly repressed in glu1-2 leaves. BHLHO39 has been shown to be downregulated by jasmonic acid (JA), and induced by salicylic acid (SA) [77] and iron deficiency [78]. It should be noted that these two transcription factors are also downregulated in glu1-2 roots.

DREB2C/DREB2H (dual probe At2g40340/At2g40350) are highly upregulated AP2/ERF transcription factors in glu1-2 leaves. DREB2C has been described as being heat and drought inducible and overexpression confers thermotolerance to the plants. Analysis of these plants lead the authors to hypothesise that DREB2C is a late regulator of genes under heat stress [79].

Flavonoid biosynthesis is affected in the glu1-2 mutant Flavonoids, which were revealed as affected in the gene sets, are a class of compounds that act for 


\section{glu1-2 roots glu1-2 leaves}

\section{erythrose-4-phosphate + phosphoenolpyruvate}

(1)

3-deoxy-D-arabino-heptulosonate 7-P

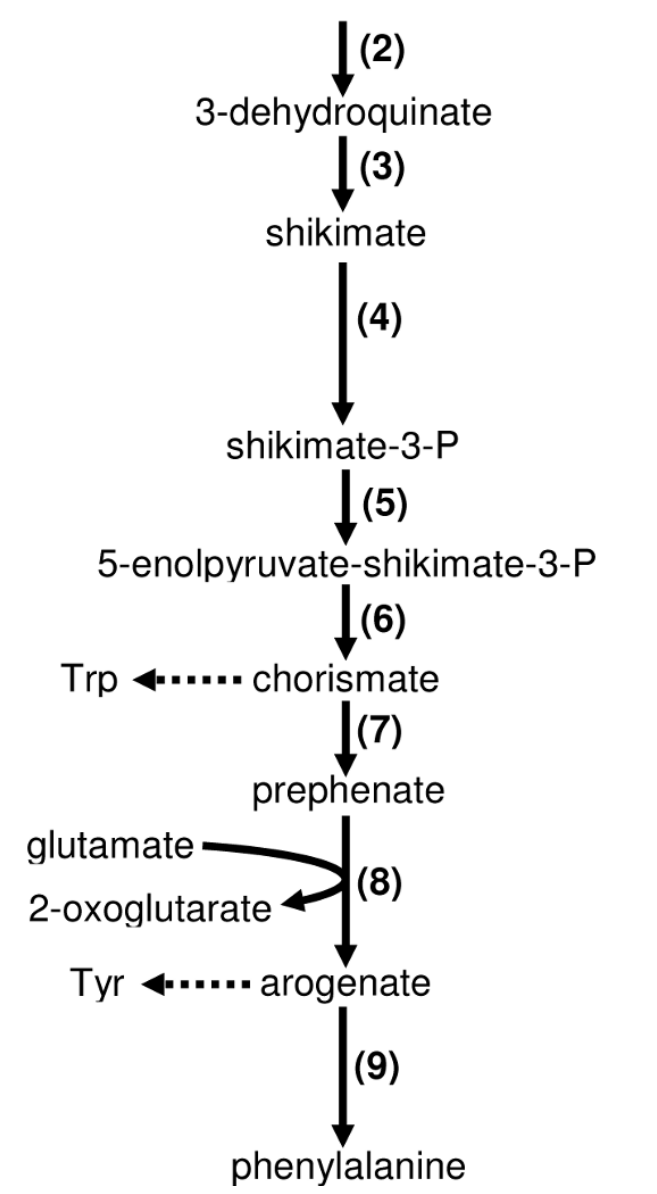

AT5G66120

AT3G06350

AT1G06890

AT2G21940

AT3G26900

AT5G47050

AT1G48850

AT2G38400

AT3G07630

AT3G44720

AT5G22630

Figure 13 Changes in gene expression in the shikimate pathway of the glu1-2 mutant. Simplified schematic representation of the shikimate pathway and the genes showing different expression levels in glu1-2 leaves and root. Gene IDs indicated in blue are upregulated whereas those indicated in red are downregulated. Enzymes: (1) 3-deoxy-D-D-arabino-heptulosonate 7-phosphate synthase (DAHPS),

(2) 3-dehydroquinate synthase (DQS), (3) 3-dehydroquinate dehydratase/shikimate dehydrogenase (DHQD), (4) shikimate kinase,

(5) 5-enolpyruvylshikimate-3-phosphate synthase, (6) chorismate synthase, (7) chorismate mutase, (8) prephenate aminotransferase, (9) arogenate dehydratase. The figure is based on [80]. The detailed data of the genes depicted in this figure are presented in Additional file 8.

example as protection against abiotic and biotic stresses and their concentrations increase in response to these [80].

Flavonoids are produced from phenylalanine which is synthesised through the shikimate pathway (Figures 13 and 14). In leaves of the glu1-2 mutant the phenylalanine metabolism was identified as being negatively affected whereas flavonoid biosynthesis was identified as being positively affected on the transcriptional level (Additional file 2). This could be interpreted as reduced levels of phenylalanine and increased amount of flavonoids and related compounds in glu1-2 mutant leaves, although tobacco plants with reduced Fd-GOGAT activity accumulate phenylalanine and tyrosine [11].

Although the expression levels of a fair number of genes implicated in the shikimate pathway were affected 


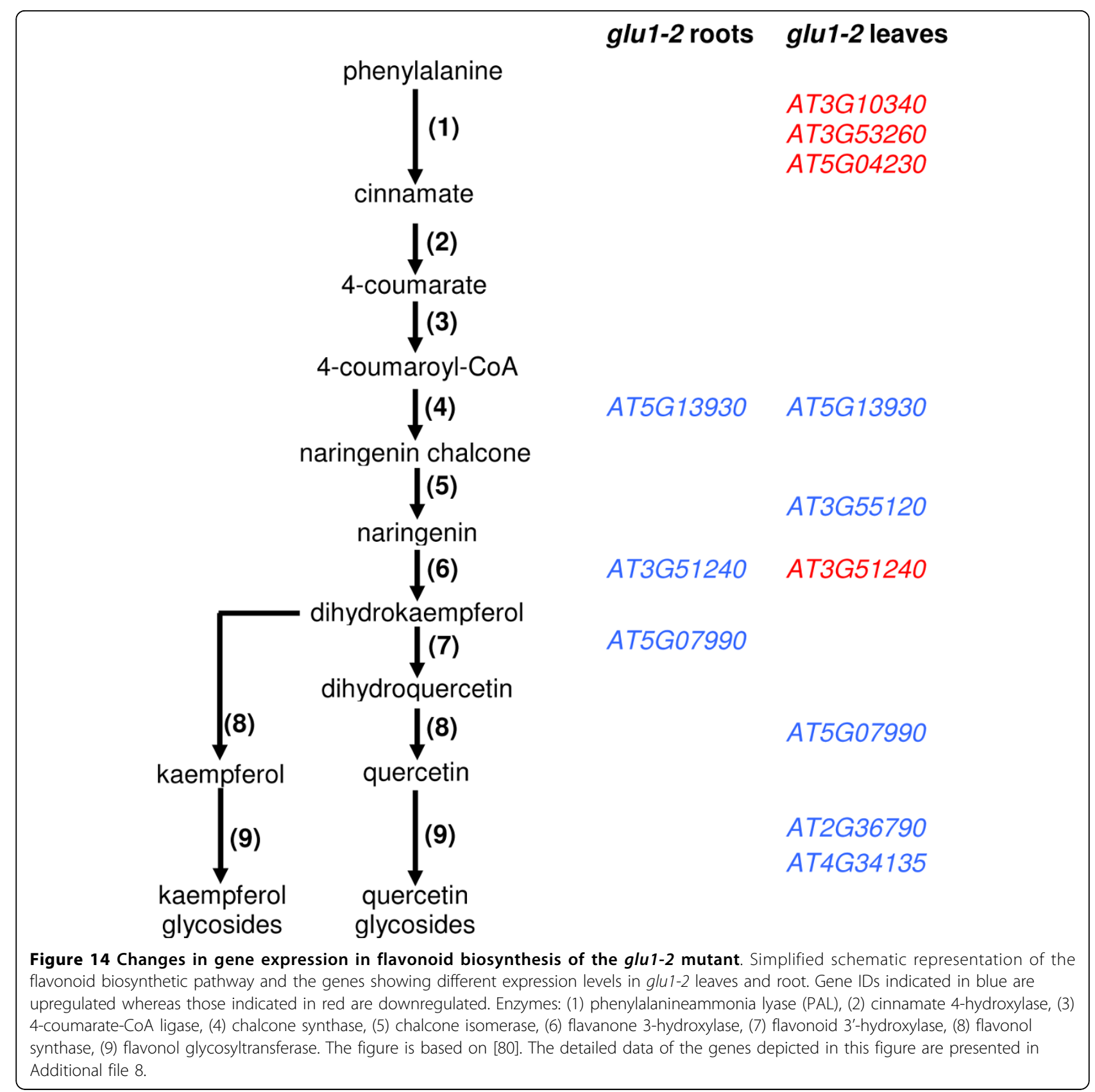

in glu1-2 leaves (Figure 13), a more detailed analysis shows that most genes are only moderately affected. In addition, no clear trend towards up- or downregulation of the pathway is visible (Additional file 8). Indeed, on one hand the genes encoding 3-deoxy-D-arabino-heptulosonate 7-phosphate synthase DAHPS that have been identified as important targets for regulation of the shikimate pathway are not affected in the glu1-2 mutant. On the other hand, the genes encoding 3- dehydroquinate synthase (DQS) and 3-dehydroquinate dehydratase (DHQD) are slightly induced in glu1-2 leaves but do not constitute important regulatory steps [80]. One of two putative prephenate aminotransferaseencoding genes (At2g38400) is downregulated in glu1-2 leaves. Prephenate aminotransferase transfers the amino group from glutamate or aspartate for the synthesis of arogenate. Genes putatively encoding arogenate dehydratase that catalyses the last step of the shikimate path- 
way leading to the formation of phenylalanine, were either induced, repressed or unaffected in glu1-2 leaves (Figure 13). This complex behaviour of the shikimate pathway in response to various treatments and its regulation by feedback mechanisms has been described [80].

As to the flavonoid pathway as such (Figure 14), it may be worth pointing out that although three (PAL2 to 4) of the four genes encoding phenylalanine ammonia lyases that putatively catalyse the first step of the phenylpropanoid pathway [80] are slightly downregulated in glu1-2 leaves, PAL1, whose effect on flavonoid accumulation has been shown, was not affected. Among the various affected genes was the gene At5g13930 encoding chalcone synthase, the first committed enzyme in flavonoid synthesis, which was upregulated in leaves and roots of the glu1-2 mutant. CHS expression has been shown to be induced by sugar, high light, UV and blue light, and phoshorus and nitrogen depletion [80]. Two genes encoding UGTs that catalyse in vitro the transfer of glucose from UDP-glucose to the 7-OH position of flavonols were among the twenty most highly upregulated ones in glu1-2 leaves: UGT73B1 [81] and UGT73C6 [82]. UGTs that are involved in flavonoid biosynthesis are essential for the accumulation of flavonoids [80]. It should however be noted that the UGT73C6 is recognised by a probe that also recognises UGT73C5 and the increased signal could therefore also be due to an increased expression of the latter. UGT73C5 is responsible for glycosylating brassinosteroids [83].

In glu1-2 roots, PathExpress identifies flavonoid biosynthesis in both down- and upregulated genes, whereas it was revealed by GeneBins only among downregulated genes (Additional files 3 and 4). This downregulation of genes in roots is however hard to sustain by looking at the reduced number of affected genes whose role in this pathway has been confirmed. As to the regulators of the flavonoid biosynthetic pathway, PAP1/MYB75 is the only implicated transcription factor that is affected in glu1-2 roots, where it is slightly upregulated (Additional file 8). PAP1/MYB75 is a positive regulator of the flavonoid biosynthetic pathway and is strongly induced by nitrogen deficiency [80]. However the genes encoding PAP2 and MYB12, two other transcription factors of this pathway that are also induced by nitrogen deficiency [80], are not affected in the glu1-2 mutant.

The multidrug resistance-related protein (MRP)-type $\mathrm{ABC}$ transporters have been implicated in the vacuolar sequestration of phenolic compounds such as flavonoids and anthocyanins, and flavonoids have been suggested as negative regulators of MDR-type members (for review: [84]). A long distance transport of flavonoids by the MRP-type of $A B C$ transporters was also recently suggested, although the transporter and the mechanism were not identified [85]. In total, 11 of the 15 AtMRPencoding genes are induced in glu1-2 leaves, whereas only two are affected in glu1-2 roots (Additional file 9). The AtMRP2 to AtMRP5 are ATP-dependent pumps for organic ions [86] and, interestingly, AtMRP2 and AtMRP3 are able to transport glutathione S-conjugates and chlorophyll catabolites into vacuoles $[87,88]$. AtMRP4 [89] and AtMRP5 are supposedly involved in regulating ion channel activities in guard cells but also have transport activity: folate for AtMRP4 and $E_{2} 17 \mathrm{G}$ for AtMRP5. Folate mediates large metabolic fluxes mainly during photorespiration as a cofactor of the mitochondrial GDC/SHM (mentioned before) complex [86]. The roles of the other MRP transporters affected in glu1-2 leaves have not yet been described, although the contribution of AtMRP12 in detoxification seems to be marginal [88] and AtMRP15 may possibly constitute a pseudogene [90]. Based on gene expression, Klein et al. [86] speculate that AtMRP14 could be involved in processes controlling seed integrity and germination efficiency such as the regulation of dormancy.

Cytochrome P450 monooxygenase-encoding genes are affected in the glu1-2 mutant Another group of enzymes related to stress response are cytochrome P450 monooxygenases. They are known to be involved in the synthesis of structural components, hormones, signalling molecules (e.g. SA and JA) and defense compounds (flavonoids, phytoalexins, glucosinolates). A large number of cytochrome $\mathrm{P} 450 \mathrm{~s}$ are responsive to hormones, signaling molecules and environmental stresses (for review: [91]). The functions of most of the 245 members of this group of enzymes in A. thaliana have not yet been identified, and it is therefore impossible to attribute most of these to particular pathways. Cytochrome P450s are categorised into the gene ontology term GO:0006118 (electron transport), which was revealed as being overrepresented (together with its parent GO:0006091) by GOstat analysis (Additional file 2).

In the glu1-2 mutant cytochrome P450 were especially frequent among the most upregulated and downregulated genes in roots. In total 22 and 39 genes annotated as encoding cytochrome P450 are affected in roots and leaves respectively (Additional file 10), indicating that proportionally a greater number of cytochrome P450s were responsive in roots.

Of the 22 genes affected in roots, 9 are repressed and 13 are induced (Additional file 10). Five cytochrome P450 encoding genes (CYP712A1, 76G1, 93D1, 716A2, $96 A 12$ in descending order of induction) are among the $10 \%$ most highly induced genes and all but one are 
specifically affected in roots. On the other hand, the genes encoding the cytochrome P450s CYP71A12, CYP82C4 and CYP81F2 were among the 10\% most highly repressed genes in glu1-2 roots. The function of CYP71A12and CYP82C4 has not yet been described. It was however shown that CYP71A12 expression responded in a similar way to aphid infestation than CYP71B15, which is involved in synthesis of the defence compound camalexin [92]. The role of CYP81F2 in the synthesis of indole glucosinolates, another group of compounds involved in plant defence, was recently reported [93]. In the glu1-2 mutant these three genes are repressed in roots while they are induced in leaves. The genes encoding three cytochrome P450 (i.e. CYP79B2, CYP79B3 and CYP83A1) involved in the biosynthesis of glucosinolates are on the other hand induced in glu1-2 roots.

In glu1-2 leaves, 20 cytochrome P450s were induced whereas 16 were repressed (Additional file 10). The two cytochrome P450-encoding genes that show the highest induction in glu1-2 leaves are At3g28740 (CYP81D11) and At4g37370 (CYP81D8). These genes, together with At3g14660 (CYP72A13), were among the 30 genes upregulated by cis-jasmone treatment [94]. CYP81D8 is also among the eight genes induced early on by imidazolinone treatment, a herbicide inhibiting acetohydroxyacid synthase (AHAS; EC 2.2.1.6) catalysing the first step of valine, isoleucine and leucine synthesis (Figure 8; [95]). Expression of CYP81D11 is induced by the application of various chemicals, such as 2,4-D and SA, and bacterial infestation [96]. These and other cytochrome P450encoding genes upregulated in glu1-2 leaves are also particularly responsive to abiotic stresses such as oxidative stress, osmotic stress, cold, heat and salt [97]. Analysis of genes co-expressed with CYP81D8 and CYP81D11 [97] could also indicate a role in phenylpropanoid biosynthesis. Similarly, cytochrome P450 genes showing the highest downregulation in leaves could be associated with photosynthesis related processes, based on co-expression analysis [97].

The detoxification of secondary metabolites and xenobiotics is induced in glu1-2 Another indication that glu1-2 mutants deploy a general stress response is the change in expression of genes involved in the detoxification of secondary metabolites and xenobiotics.

Some of the cytochrome P450-encoding genes that are affected in the glu1-2 mutant may play a role in the phase I of this detoxification [98].

Glutathione S-transferases (EC 2.5.1.18; GSTs), also known as glutathione transferases (GTs), are involved in the second phase of detoxification processes. These enzymes catalyse the conjunction of glutathione (GSHtripeptide) with electrophilic compounds, to form non toxic derivatives that are ready to be compartimentalised in vacuoles. In addition, GSTs can serve as peroxidases, isomerases and thiol transferases or have non-catalytic functions such as ligand binding and modulation of signalling processes (for review: [99]). Several studies that have analysed the responsiveness of AtGSTs to different stimuli have revealed the complex nature of the regulation of these genes (for review: [100]). In glu1-2 leaves the expression of 26 genes coding for (putative) GSTs belonging to the tau (GSTU), phi (GSTF) and zeta (GSTZ) classes are affected, 20 of these being induced and 6 being repressed. In glu1-2 roots, four glutathione S-transferases are induced and two are repressed (Additional file 11). Eight GSTU-encoding genes are among the 5\% most upregulated genes in glu1-2 leaves and AtGSTU24 (At1g17170), the most highly induced of them, was reported to be induced by herbicide treatment, xenobiotic exposure and in the catalase 2 deficient mutant (characterised by intracellular redox perturbation and activation of oxidative signalling). It was hypothesised that AtGSTU24 could be involved in the conjugation of stress-induced catabolites ([101] and references therein). AtGSTU24 has also been shown to be SA inducible [102]. Several of the other highly upregulated GSTU-encoding genes, such as GSTU1, 2, 4, 7, 9, 19, 22, 25 are induced in response to salt stress [103]. As to members of the phi class that are induced in glu1-2 leaves, AtGSTF6/GSTF7 (At1g02930/At1g02920 dual probe) are responsive to cold and heat stress, oxidative damage and metal exposure [104]. AtGSTF2 has also been shown to be responsive to several stimuli and the protein interacts with flavonoids in vitro [105].

UDP-glycosyltransferases (UGTs) use UDP-activated sugars as donor to catalyse the glycosylation of various metabolites and are hence implicated in a series of mechanisms and pathways, including phase II of the detoxification mechanism.

In glu1-2 mutant leaves 45 UGT-encoding genes are affected, which represents a third of the approximately 120 UGT-encoding genes that have been identified in the A. thaliana genome (for review: [106]). Thirty-six are induced in glu1-2 leaves and fourteen of these are among the top 5\% induced genes (Additional file 12). UGT73B1 and UGT73C6, already mentioned above, are involved in flavonoid biosynthesis [81,82]. In vitro essays with UGT73B4 (At2g15490) showed that it was able to glycosylate both the $3-\mathrm{OH}$ and the $4-\mathrm{OH}$ position of the benzoate derivative 3,4-dihydroxybenzoic acid [107]. UGT75B1 (At1g05560) is associated with the callose synthase complex [108] and is highly induced in oxidative stress catalase 2 deficient mutants [101]. UGT84A3 (At4g15490) may be involved in sinapate ester metabolism in plants [109]. Three genes encoding UGTs that may be involved in cytokinin glycosylation [110] were also affected in glu1-2 leaves: UGT73C1 (At2g36750), 
UGT85A1 (At1g22400) and UGT76C1 (At5g05870). Recombinant UGT73C1 is also able to conjugate transformation products of the explosive 2,4,6-trinitrotoluene [111]. UGT84B1 (also known as IAGLU) glucosylates indole-3-acetic acid [112] and the encoding gene At4g15550 is also upregulated in glu1-2 leaves. UGT74F2 (At2g34820) has been described as a salicylic acid glucosyltransferase $[107,113]$ and it has also been hypothesised as playing a role in tryptophan biosynthesis [114].

Several of the UGT-encoding genes that are highly upregulated in glu1-2 leaves have been shown to be stress responsive. Recently, UGT74E2 (At1g05680) was identified as one of eight genes that were rapidly and highly induced upon treatment with the herbicide imidazolinone [95]. This gene was the most highly induced in glu1-2 leaves. UGT73B1, UGT73B2 and UGT73B3 have been implicated in the response to oxidative stress and a role in stress response and resistance to Pseudomonas syringae was shown for UGT73B3 and UGT73B5 $[115,116]$.

Phase III of xenobiotic detoxification in plants consists of storage of the compounds produced by the mechanisms of two first phases. The multidrug and toxic compound extrusion (MATE) efflux carriers may function in this process, although the transport activities and exact roles of most of these have not yet been described [117]. Fourteen of the 58 MATE protein-encoding gene of $A$. thaliana are induced and five are repressed in glu1-2 leaves (Additional file 13). Three are among the top fourteen induced genes in glu1-2 leaves: AtDTX1 (At2g04040), AtDTX3 (At2g04050) and AtDTX4 (At2g04070). AtDTX1 serves as an efflux carrier for plant derived alkaloids [118]. To our knowledge, the functions of AtDTX3 and AtDTX4 have not yet been reported but AtDTX4 was also among the genes that were rapidly induced by the herbicide imidazolinone [95].

Numerous other responsive genes linked to a number of different stresses/stimuli are induced in glu1-2 leaves Besides the stress responsive genes and those involved in detoxification mechanisms that were discussed in more detail above, numerous other stressrelated genes were affected in the glu1-2 mutant. It is beyond the scope of the present article to describe these in detail. This can however be exemplified by the striking overlap between the genes induced in leaves of the glu1-2 mutant and those described by Vanderauwera et al. [119] in the catalase 2 deficient CAT2HP1 plant. Of the 55 genes induced more than 3 fold in the CAT2HP1 plant, 45 were also induced in glu1-2 mutant leaves (Additional file 14), including cytochrome P450-, GST- and UGT-encoding genes already mentioned above. Other similarities in transcriptional responses can be detected between glu1-2 mutant plants and plants submitted to cold treatment [73], heat stress [120] and herbicide treatment [95](data not shown). This also exemplifies that the transcriptional response of the glu12 mutant bears the signatures of a multiple stress response.

\section{Conclusions}

Knocking down the expression of the gene Fd-GOGAT1 coding for one of the two ferredoxin-dependent glutamate synthases, which catalyse the ultimate step in the biosynthesis of glutamate, and a key enzyme in the assimilation of inorganic nitrogen, has marked effects on the transcriptome of the plant as evidenced by our microarray analysis of the glu1-2 mutant. Even more so as the assayed plants were grown in vitro on $1 \mathrm{x}$ MS media supplemented with $3 \%$ sucrose, and nitrogen supply should not be limiting either under these conditions. Hence, the transcriptional profiling should be viewed under the angle that the growth conditions that were used in the present study do not constitute the most severe conditions possible for the glu1-2 mutant. This is also indicated by the fact that the glu1-2 mutant described here develops more slowly than wild-type plants when grown on soil, but does eventually complete its life cycle (data not shown). The Fd-GOGAT1 deficient $A$. thaliana mutants described previously display a lethal phenotype $[5,7,9]$. It should however be noted that the growth conditions for the glu1-2 mutant used here, did not prevent plants from showing a chlorotic phenotype, although less severe than in previously published studies.

As Fd-GOGAT1 expression is much higher in leaves than in roots of A. thaliana at the steady state ([5]; Additional file 1), the effects were expectedly of a larger scale in the leaves than in the roots, both in regard to the number of affected genes and the levels of regulation. The level of downregulation of $F d-G O G A T 1$ itself in the glu1-2 mutant is also much more pronounced in leaves than in roots.

Although an effect can be seen on the expression levels of genes involved in primary nitrogen assimilation, glutamate metabolism and related pathways, the number of such genes affected and the scale of changes are more moderate than we expected. This may be explained by the fact that the defect in primary nitrogen assimilation exhibited by Fd-GOGAT mutants are specific to conditions when photorespiration is suppressed [5], which is not the case under the experimental conditions chosen here. Upregulation of Fd-GOGAT 2 and $N A D H-G O G A T$ may also compensate to some extent 
for the loss of Fd-GOGAT1. Metabolic profiling confirmed the expected increase in glutamine levels in the glu1-2 mutant but revealed also changes in the levels of other amino acids.

Photosynthesis and related pathways are overall downregulated, which is consistent with the chlorotic phenotype of the glu1-2 mutant and the reduced amount of total chlorophyll measured in $g l s$ mutants [5]. The flavonoid biosynthesis was also revealed as being affected, although a more detailed analysis of the affected genes did not reveal major changes in expression levels, except for genes involved in the production of flavonoid glycosides.

The most pronounced effect at the transcriptomic level could however be seen on genes that are responsive to abiotic stresses and stimuli. Genes that had been described before as being responsive to cold, heat and drought could be identified as being upregulated in the glu1-2 mutant, mostly in leaves. Especially striking is the way that oxidative stress response genes and genes involved in detoxification of secondary metabolites are affected in the glu1-2 mutant.

Fd-GOGAT plays an important role in the photorespiratory cycle by participating in the reassimilation of released ammonia. Deregulation of photorespiration in the glu1-2 mutant may lead to a reduced elimination of excess excitation energy, and hence an imbalance in the redox status. In addition $\mathrm{NH}_{4}{ }^{+}$that accumulates due to the lack of reassimilation through the GS/GOGAT cycle may be perceived by the plant as a toxic compound, triggering a global stress response.

\section{Methods}

\section{Plant material}

The A. thaliana T-DNA insertion line SALK_019917 for Fd-GOGAT1 (At5g04140) was identified in the SALK TDNA insertion mutant collection [121], seeds were obtained from the European Arabidopsis Stock Centre NASC [122] and homozygous mutant plants (called glu1-2) were obtained. The T-DNA insertion was checked by PCR amplification using a T-DNA primer and a Fd-GOGAT1 specific primer, and subsequent sequencing of the amplicon. A. thaliana ecotype Col-0 was used as wild-type control in all described assays.

\section{Plant growth conditions}

Wild-type Col-0 and mutant glu1-2 seeds were surface sterilised and sown on solid in vitro cultivation medium consisting of 1x Murashige and Skoog basal salt mixture, $3 \%$ sucrose, $0.75 \%$ phytoagar (w/v), pH5.7. This medium contains $1650 \mathrm{mg}$ ammonium nitrate/L. Seeds were stratified for 3 days at $4{ }^{\circ} \mathrm{C}$ before being transferred to a controlled growth chamber under a 16 hour photoperiod (light intensity: $75 \mu \mathrm{mol} \cdot \mathrm{m}^{-2} \cdot \mathrm{sec}^{-1}$ ) at $21-23^{\circ} \mathrm{C}$.

\section{Microarray analysis}

For microarray experiments of wild-type and glu1-2 mutant plants, four biological replicates of each were processed simultaneously through the following procedure. Leaves and roots of 18 day old in vitro grown plantlets were harvested separately and immediately flash-frozen in liquid $\mathrm{N}_{2}$. Harvesting of tissue was performed two hours after onset of the 16 hour light period. The harvested tissue was stored at $-80^{\circ} \mathrm{C}$ until further processing. Total RNA was extracted from plant tissue (300 mg roots, $500 \mathrm{mg}$ leaves) using the RNeasy Plant Midi kit (Qiagen, Hilden, Germany) following the supplier's instructions. RNasin (Promega, Madison, USA) was added to the RNA to the final concentration of $1 \mathrm{U} / \mu \mathrm{l}$. RNA quality was assessed by standard denaturing agarose gel electrophoresis and RNA concentration was measured with a NanoDrop ND-1000 (Nanodrop, Delaware, USA). To prepare the samples for microarray experiments the "GeneChip Expression Analysis" procedure of Affymetrix (Santa Clara, USA) was followed. Briefly, 10 $\mu \mathrm{g}$ total RNA was processed through a one-cycle cDNA synthesis procedure, the resulting double-stranded cDNA was cleaned up and submitted to the synthesis of biotinlabelled cRNA. This biotin-labelled cRNA was then cleaned up, quantified and fragmented before being hybridized to Affymetrix GeneChip Arabidopsis ATH1 genome arrays. After 16 hours of hybridization the arrays were processed through the washing and staining procedures, before being scanned and analysed. Microarray data files have been deposited in the Gene Expression Omnibus (GEO accession number: GSE20493).

\section{Statistical analysis of microarray data}

The microarray data were preprocessed using the Robust Multichip Average (RMA) package [123] as implemented in $\mathrm{R}$ [124]. The data were normalized using quantile normalization, and expression measures were produced by fitting the RMA robust linear model. Differentially regulated genes were identified using moderated t-tests discussed in [125] and implemented in the Limma package for R. To adjust for the large number of hypothesis tests made, the q-value [126] associated with each p-value was also calculated. The q-value for a gene is the expected proportion of false positives one will get when calling that gene significant. For a gene to be considered significantly differentially expressed in this experiment its q-value was required to be lower than 0.01 . In effect, this means controlling the false discovery rate (FDR) [127] in the experiment at a 0.01 level.

\section{Genome annotation}

Genome annotation as given in the tables originates from Affymetrix (Santa Clara, USA). This was supplemented/updated by information provided by The 
Arabidopsis Information Service (TAIR; [128]) and the Salk Institute Genomic Analysis Laboratory (SIGnAL; [121]).

Biochemical pathways were assessed according to published data (see referred articles at the respective places in the text) and information provided by the AraCyc database [129], the Kyoto Encyclopedia of Genes and Genomes (KEGG; [130]) and the Expert Protein Analysis System (ExPASy; [131]).

Classification into GO terms were taken over from the software in question (e.g. GOstat, MapMan) but AmiGO [132] and the GO annotation at TAIR [128] were used for more extensive searches.

\section{NMR spectroscopy of total metabolites and principal component analysis (PCA)}

Total metabolites were extracted from freeze-dried plant material according to Liang et al. [133] with some modifications. Fresh plant material $(0.5 \mathrm{~g})$ was freeze-dried and extracted with $1.5 \mathrm{ml}$ mixture of $\mathrm{KH}_{2} \mathrm{PO}_{4}$ buffer (90 $\mathrm{mM}, \mathrm{pH}$ 6.0) in $\mathrm{D}_{2} \mathrm{O}$ containing $0.05 \%$ TSP (trimethylsilyl propionic acid sodium salt, w/v) and methanol- $d_{4}$ (1:1). The extract was vortexed for $30 \mathrm{~s}$, centrifuged at $4500 \mathrm{rpm}$ for $10 \mathrm{~min}$ and filtered through glass wool. Five hundred microliters of the supernatant were taken for NMR spectroscopy analysis.

NMR spectroscopy was performed at $25^{\circ} \mathrm{C}$ on a Bruker DRX 600 spectrometer (Bruker, Rheinstetten, Germany) resonating at $600.13 \mathrm{MHz}$ fitted with a $5 \mathrm{~mm}$ $\mathrm{BBO}$ probe. The frequency lock was done on MeOD. 1D ${ }^{1} \mathrm{H}$-NMR spectra were recorded with presaturation of the residual water resonance in the interscan delay using a standard Bruker pulse sequence (zgpr). A $90^{\circ}$ excitation pulse was used to record 256 FID's with a spectral width of $8389 \mathrm{~Hz}$ averaged into $32 \mathrm{k}$ data points with an acquisition time of $3.91 \mathrm{~s}$. The interscan delay was $3 \mathrm{~s} .{ }^{1} \mathrm{H},{ }^{1} \mathrm{H}$-COSY NMR spectra with the same spectral width as the 1D spectra were recorded with $2048 \times 512$ data points in the F2xF1 directions. Presaturation of the residual water resonance was done in the interscan delay using a standard Bruker pulse sequence (cosyqfpr). 16 FID's were recorded for each increment in the F1 direction. A square sine bell window function was applied in both directions and zero filling in the F1 direction was applied to give the processed spectrum a resolution of $2048 \times 2048$ data points.

The NMR spectra were exported from TOPSPIN and imported into R [124] where the datasets were compiled. SpecAlign [134] was used for peak alignment of the spectra. Principal Component Analysis (PCA) was performed in $\mathrm{R}$ using the pls library of Mevik et al[135]. The loading plots from the analyses were used to identify the resonances that were different between the groups.
Additional file 1: Transcriptional data of glu1-2. Detailed lists of genes whose expression is affected in leaves and roots of 18 day old g/u1-2 mutant plants

Additional file 2: GOstat analysis of glu1-2 transcriptional data. GO_biological_process terms identified by GOstat [13] as being overrepresented ( $P=0.01$ with FDR/Benjamini correction) among the genes affected in g/u1-2 mutant leaves and roots.

Additional file 3: PathExpress analysis of glu1-2 transcriptional data. Identification by PathExpress [14] of affected pathways among the sets of genes whose expression is affected in the glu1-2 mutant.

Additional file 4: GeneBins analysis of glu1-2 transcriptional data. BINs identified by GeneBins [15] as being affected in the datasets of genes that show a different expression in glu1-2 organs compared to wild type.

Additional file 5: 2-oxoglutarate synthesis and TCA cycle. Genes whose expression is affected in g/u 1-2 mutant leaves and that encode enzymes involved in 2-oxoglutarate synthesis and the TCA cycle.

Additional file 6: Photosynthesis and related pathways. Genes whose expression is affected in glu 1-2 mutant leaves and roots and that encode enzymes involved in photosynthesis related $\mathrm{GO}$ categories and bins as identified by GOstat [13], AmiGO [132] and MapMan [12] respectively.

Additional file 7: Transcription factors. Genes encoding WRKY, $\mathrm{C} 2 \mathrm{H} 2$, $\mathrm{CCCH}, \mathrm{MYB}, \mathrm{bHLH}$ or AP2/ERF transcription factors and that show different expression in the g/u1-2 mutant.

Additional file 8: Shikimate pathway and flavonoid biosynthesis. Genes implicated in the shikimate pathway and flavonoid biosynthesis, and that show different expression in the glu1-2 mutant.

Additional file 9: ABC transporters. Genes whose expression is affected in the glu1-2 mutant and that encode ABC transporters.

Additional file 10: Cytochrome P450 monooxygenases. Cytochrome P450-encoding genes whose expression is affected in the glu1-2 mutant.

Additional file 11: Glutathione S-transferases. Genes encoding glutathione S-transferases (GSTs) and that show different expression in the glu1-2 mutant.

Additional file 12: UDP-glycosyltransferases. Genes encoding UDPglycosyltransferases (UGTs) and that show different expression in the glu1-2 mutant.

Additional file 13: MATE efflux family proteins. Genes coding for multidrug and toxic compound extrusion (MATE) efflux carriers and that show different expression in the glu1-2 mutant.

Additional file 14: Comparison with catalase 2 deficient plants. Comparison of induced transcriptional responses in catalase 2 deficient plants CAT2HP1 and g/u1-2 mutant leaves.

\section{Acknowledgements}

This work was funded by grants from the Norwegian Research Council (NFR). We would like to thank Torfinn Sparstad and Marianne Nymark for excellent technical assistance.

\section{Author details}

'Department of Biology, Norwegian University of Science and Technology (NTNU), NO-7491 Trondheim, Norway. ${ }^{2}$ SINTEF Fisheries and Aquaculture, NO-7465 Trondheim, Norway. ${ }^{3}$ Current address: Scandpower AS, NO-7462 Trondheim, Norway. ${ }^{4}$ Current address: Department of Cancer Research and Molecular Medicine, Norwegian University of Science and Technology (NTNU), NO-7489 Trondheim, Norway.

\section{Authors' contributions}

RK, PW, TSJ, DHTT, TRS and AMB drafted the manuscript. RK and PW analysed the transcriptional data. TSJ performed statistical analysis of the transcriptional data. TRS performed NMR spectroscopy and analysed NMR results. TC performed the verification of the T-DNA insertion mutant and a preliminary microarray characterisation on a home-made $2 \mathrm{~K}$ chip. PW, DHTT and $A M B$ designed the study and AMB coordinated the study. All authors read and approved the final manuscript. 
Received: 26 October 2009 Accepted: 22 March 2010

Published: 22 March 2010

\section{References}

1. Coruzzi GM: Primary N-assimilation into amino acids in Arabidopsis. The Arabidopsis Book Rockville: American Society of Plant BiologistsSomerville C, Meyerowitz EM 2003.

2. Linka M, Weber APM: Shuffling ammonia between mitochondria and plastids during photorespiration. Trends Plant Sci 2005, 10:461-465.

3. Wingler A, Lea PJ, Quick WP, Leegood RC: Photorespiration: metabolic pathways and their role in stress protection. Philos Trans $R$ Soc Lond B Biol Sci 2000, 355:1517-1529.

4. Suzuki A, Knaff DB: Glutamate synthase: structural, mechanistic and regulatory properties, and role in the amino acid metabolism. Photosynth Res 2005, 83:191-217.

5. Coschigano KT, Melo-Oliveira R, Lim J, Coruzzi GM: Arabidopsis gls mutants and distinct Fd-GOGAT genes: Implications for photorespiration and primary nitrogen assimilation. Plant Cell 1998, 10:741-752.

6. Zimmermann P, Hirsch-Hoffmann M, Hennig L, Gruissem W: GENEVESTIGATOR. Arabidopsis microarray database and analysis toolbox. Plant Physiol 2004, 136:2621-2632.

7. Suzuki A, Rothstein S: Structure and regulation of ferredoxin-dependent glutamase synthase from Arabidopsis thaliana - Cloning of CDNA expression in different tissues of wild-type and glts mutant strains, and light induction. Eur J Biochem 1997, 243:708-718.

8. Jamai A, Salomé PA, Schilling SH, Weber APM, McClung CR: Arabidopsis photorespiratory serine hydroxymethyltransferase activity requires the mitochondrial accumulation of ferredoxin-dependent glutamate synthase. Plant Cell 2009, 21:595-606.

9. Somerville CR, Ogren WL: Inhibition of photosynthesis in Arabidopsis mutants lacking leaf glutamate synthase activity. Nature 1980 286:257-259

10. Kendall AC, Wallsgrove RM, Hall NP, Turner JC, Lea PJ: Carbon and nitrogen-metabolism in barley (Hordeum vulgare L.) mutants lacking ferredoxin-dependent glutamate synthase. Planta 1986, 168:316-323.

11. Ferrario-Méry S, Suzuki A, Kunz C, Valadier MH, Roux Y, Hirel B, Foyer CH: Modulation of amino acid metabolism in transformed tobacco plants deficient in Fd-GOGAT. Plant Soil 2000, 221:67-79.

12. Thimm $O$, Blasing $O$, Gibon $Y$, Nagel A, Meyer $S$, Kruger $P$, Selbig J, Muller LA, Rhee SY, Stitt M: MAPMAN: a user-driven tool to display genomics data sets onto diagrams of metabolic pathways and other biological processes. Plant J 2004, 37:914-939.

13. Beissbarth T, Speed TP: GOstat: find statistically overrepresented Gene Ontologies within a group of genes. Bioinformatics 2004, 20:1464-1465.

14. Goffard N, Weiller G: PathExpress: a web-based tool to identify relevant pathways in gene expression data. Nucleic Acids Res 2007, 35:W176-W181.

15. Goffard N, Weiller G: GeneBins: a database for classifying gene expression data, with application to plant genome arrays. BMC Bioinformatics 2007, $8: 87$.

16. Shannon P, Markiel A, Ozier O, Baliga NS, Wang JT, Ramage D, Amin N, Schwikowski B, Ideker T: Cytoscape: A software environment for integrated models of biomolecular interaction networks. Genome Res 2003, 13:2498-2504

17. Bindea G, Mlecnik B, Hackl H, Charoentong P, Tosolini M, Kirilovsky A, Fridman WH, Pages F, Trajanoski Z, Galon J: ClueGO: a Cytoscape plug-in to decipher functionally grouped gene ontology and pathway annotation networks. Bioinformatics 2009, 25:1091-1093.

18. Lam HM, Coschigano K, Schultz C, Melooliveira R, Tjaden G, Oliveira I, Ngai N, Hsieh MH, Coruzzi G: Use of Arabidopsis mutants and genes to study amide amino acid biosynthesis. Plant Cell 1995, 7:887-898.

19. Toufighi K, Brady SM, Austin R, Ly E, Provart NJ: The Botany Array Resource: e-Northerns, Expression Angling, and promoter analyses. Plant J 2005, 43:153-163

20. Usadel B, Blasing OE, Gibon Y, Poree F, Hohne M, Gunter M, Trethewey R, Kamlage B, Poorter H, Stitt M: Multilevel genomic analysis of the response of transcripts, enzyme activities and metabolites in Arabidopsis rosettes to a progressive decrease of temperature in the non-freezing range. Plant Cell Environ 2008, 31:518-547.

21. Masclaux-Daubresse C, Reisdorf-Cren M, Pageau K, Lelandais M, Grandjean O, Kronenberger J, Valadier MH, Feraud M, Jouglet T, Suzuki A: Glutamine synthetase-glutamate synthase pathway and glutamate dehydrogenase play distinct roles in the sink-source nitrogen cycle in tobacco. Plant Physiol 2006, 140:444-456.

22. Taira M, Valtersson U, Burkhardt B, Ludwig RA: Arabidopsis thaliana GLN2 encoded glutamine synthetase is dual targeted to leaf mitochondria and chloroplasts. Plant Cell 2004, 16:2048-2058.

23. Ferrario-Méry S, Masclaux C, Suzuki A, Valadier MH, Hirel B, Foyer CH: Glutamine and alpha-ketoglutarate are metabolite signals involved in nitrate reductase gene transcription in untransformed and transformed tobacco plants deficient in ferredoxin-glutamine-alpha-ketoglutarate aminotransferase. Planta 2001, 213:265-271.

24. Lea PJ, Sodek L, Parry MAJ, Shewry R, Halford NG: Asparagine in plants. Ann Appl Biol 2007, 150:1-26.

25. Lam HM, Wong P, Chan HK, Yam KM, Chen L, Chow CM, Coruzzi GM: Overexpression of the ASN1 gene enhances nitrogen status in seeds of Arabidopsis. Plant Physiol 2003, 132:926-935

26. Lea PJ, Azevedo RA: Nitrogen use efficiency. 2. Amino acid metabolism. Ann Appl Biol 2007, 151:269-275.

27. Igarashi D, Miwa T, Seki M, Kobayashi M, Kato T, Tabata S, Shinozaki K Ohsumi C: Identification of photorespiratory glutamate:glyoxylate aminotransferase (GGAT) gene in Arabidopsis. Plant J 2003, 33:975-987.

28. Miyashita Y, Dolferus R, Ismond KP, Good AG: Alanine aminotransferase catalyses the breakdown of alanine after hypoxia in Arabidopsis thaliana. Plant J 2007, 49:1108-1121.

29. Bauwe H, Kolukisaoglu U: Genetic manipulation of glycine decarboxylation. J Exp Bot 2003, 54:1523-1535.

30. Engel N, Daele van den K, Kolukisaoglu U, Morgenthal K, Weckwerth W, Parnik T, Keerberg O, Bauwe H: Deletion of glycine decarboxylase in Arabidopsis is lethal under nonphotorespiratory conditions. Plant Physiol 2007, 144:1328-1335.

31. Voll LM, Jamai A, Renne P, Voll H, McClung CR, Weber APM: The photorespiratory Arabidopsis shm 1 mutant is deficient in SHM1. Plant Physiol 2006, 140:59-66.

32. Slocum RD: Genes, enzymes and regulation of arginine biosynthesis in plants. Plant Physiol Biochem 2005, 43:729-745.

33. Binder $\mathrm{S}$, Knill T, Schuster J: Branched-chain amino acid metabolism in higher plants. Physiol Plant 2007, 129:68-78.

34. Meyer AJ: The integration of glutathione homeostasis and redox signaling. J Plant Physiol 2008, 165:1390-1403.

35. Turano FJ, Fang TK: Characterization of two glutamate decarboxylase cDNA clones from Arabidopsis. Plant Physiol 1998, 117:1411-1421.

36. Zik M, Arazi T, Snedden WA, Fromm H: Two isoforms of glutamate decarboxylase in Arabidopsis are regulated by calcium/calmodulin and differ in organ distribution. Plant Mol Biol 1998, 37:967-975.

37. Miyashita Y, Good AG: Contribution of the GABA shunt to hypoxiainduced alanine accumulation in roots of Arabidopsis thaliana. Plant Cell Physiol 2008, 49:92-102.

38. Fontaine JX, Saladino F, Agrimonti C, Bedu M, Terce-Laforgue T, Tetu T, Hirel B, Restivo FM, Dubois F: Control of the synthesis and subcellular targeting of the two GDH genes products in leaves and stems of Nicotiana plumbaginifolia and Arabidopsis thaliana. Plant Cell Physiol 2006, 47:410-418.

39. Miyashita Y, Good AG: NAD(H)-dependent glutamate dehydrogenase is essential for the survival of Arabidopsis thaliana during dark-induced carbon starvation. J Exp Bot 2008, 59:667-680.

40. Purnell MP, Botella JR: Tobacco isoenzyme 1 of $\mathrm{NAD}(\mathrm{H})$-dependent glutamate dehydrogenase catabolizes glutamate in vivo. Plant Physiol 2007, 143:530-539

41. Lancien M, Gadal P, Hodges M: Enzyme redundancy and the importance of 2-oxoglutarate in higher plant ammonium assimilation. Plant Physiol 2000, 123:817-824

42. Ferrario-Méry S, Hodges M, Hirel B, Foyer CH: Photorespirationdependent increases in phosphoenolpyruvate carboxylase, isocitrate dehydrogenase and glutamate dehydrogenase in transformed tobacco plants deficient in ferredoxin-dependent glutamine-alpha-ketoglutarate aminotransferase. Planta 2002, 214:877-886

43. Fischer WN, Loo DDF, Koch W, Ludewig U, Boorer KJ, Tegeder M, Rentsch D, Wright EM, Frommer WB: Low and high affinity amino acid $\mathrm{H}$ ${ }^{+}$-cotransporters for cellular import of neutral and charged amino acids. Plant J 2002, 29:717-731. 
44. Lee YH, Foster J, Chen J, Voll LM, Weber APM, Tegeder M: AAP1 transports uncharged amino acids into roots of Arabidopsis. Plant J 2007, 50:305-319.

45. Hirner A, Ladwig F, Stransky H, Okumoto S, Keinath M, Harms A, Frommer WB, Koch W: Arabidopsis LHT1 is a high-affinity transporter fo cellular amino acid uptake in both root epidermis and leaf mesophyll. Plant Cell 2006, 18:1931-1946.

46. Svennerstam H, Ganeteg U, Bellini C, Nasholm T: Comprehensive screening of Arabidopsis mutants suggests the lysine histidine transporter 1 to be involved in plant uptake of amino acids. Plant Physiol 2007, 143:1853-1860.

47. Dündar E, Bush DR: BAT1, a bidirectional amino acid transporter in Arabidopsis. Planta 2009, 229:1047-1056.

48. Forde BG, Lea PJ: Glutamate in plants: metabolism, regulation, and signalling. J Exp Bot 2007, 58:2339-2358.

49. Lemaitre T, Urbanczyk-Wochniak E, Flesch V, Bismuth E, Fernie AR, Hodges M: NAD-dependent isocitrate dehydrogenase mutants of Arabidopsis suggest the enzyme is not limiting for nitrogen assimilation. Plant Physiol 2007, 144:1546-1558.

50. Tsay YF, Chiu CC, Tsai CB, Ho CH, Hsu PK: Nitrate transporters and peptide transporters. FEBS Lett 2007, 581:2290-2300

51. Guo FO, Young J, Crawford NM: The nitrate transporter AtNRT1.1 (CHL1) functions in stomatal opening and contributes to drought susceptibility in Arabidopsis. Plant Cell 2003, 15:107-117.

52. Walch-Liu P, Forde BG: Nitrate signalling mediated by the NRT1.1 nitrate transporter antagonises L-glutamate-induced changes in root architecture. Plant J 2008, 54:820-828.

53. Okamoto M, Vidmar JJ, Glass ADM: Regulation of NRT1 and NRT2 gene families of Arabidopsis thaliana: responses to nitrate provision. Plant Cell Physiol 2003, 44:304-317.

54. Okamoto M, Kumar A, Li WB, Wang Y, Siddiqi MY, Crawford NM, Glass ADM: High-affinity nitrate transport in roots of Arabidopsis depends on expression of the NAR2-like gene AtNRT3.1. Plant Physiol 2006, 140:1036-1046.

55. Orsel M, Chopin F, Leleu O, Smith SJ, Krapp A, Daniel-Vedele F, Miller AJ: Characterization of a two-component high-affinity nitrate uptake system in Arabidopsis. Physiology and protein-protein interaction. Plant Physiol 2006, 142:1304-1317

56. Ludewig U, Neuhäuser B, Dynowski M: Molecular mechanisms of ammonium transport and accumulation in plants. FEBS Lett 2007 581:2301-2308.

57. Yuan YZ, Ou JQ, Wang ZQ, Zhang CF, Zhou ZP, Lin QH: Regulation of carbon and nitrogen metabolisms in rice roots by 2-oxoglutarate at the level of hexokinase. Physiol Plant 2007, 129:296-306.

58. Geelen D, Lurin C, Bouchez D, Frachisse JM, Lelievre F, Courtial B, BarbierBrygoo H, Maurel C: Disruption of putative anion channel gene AtCLC-a in Arabidopsis suggests a role in the regulation of nitrate content. Plant $J$ 2000, 21:259-267.

59. De Angeli A, Monachello D, Ephritikhine G, Frachisse JM, Thomine S, Gambale F, Barbier-Brygoo H: The nitrate/proton antiporter AtCLCa mediates nitrate accumulation in plant vacuoles. Nature 2006 442:939-942.

60. Loqué $D$, Ludewig $U$, Yuan $L X$, von Wirén $N$ : Tonoplast intrinsic proteins AtTIP2;1 and AtTIP2;3 facilitate $\mathrm{NH}_{3}$ transport into the vacuole. Plant Physiol 2005, 137:671-680.

61. Häusler RE, Blackwell RD, Lea PJ, Leegood RC: Control of photosynthesis in barley leaves with reduced activities of glutamine-synthetase or glutamate synthase. I. Plant characteristics and changes in nitrate, ammonium and amino acids. Planta 1994, 194:406-417.

62. Dzuibany C, Haupt S, Fock H, Biehler K, Migge A, Becker TW: Regulation of nitrate reductase transcript levels by glutamine accumulating in the leaves of a ferredoxin-dependent glutamate synthase-deficient gluS mutant of Arabidopsis thaliana, and by glutamine provided via the roots. Planta 1998, 206:515-522.

63. Reumann S, Weber APM: Plant peroxisomes respire in the light: some gaps of the photorespiratory C-2 cycle have become filled - others remain. Biochim Biophys Acta 2006, 1763:1496-1510.

64. Boldt R, Edner C, Kolukisaoglu U, Hagemann M, Weckwerth W, Wienkoop S, Morgenthal K, Bauwe H: D-GLYCERATE 3-KINASE, the last unknown enzyme in the photorespiratory cycle in Arabidopsis, belongs to a novel kinase family. Plant Cell 2005, 17:2413-2420.
65. Schwarte S, Bauwe H: Identification of the photorespiratory 2phosphoglycolate phosphatase, PGLP1, in Arabidopsis. Plant Physiol 2007, 144:1580-1586.

66. Timm S, Nunes-Nesi A, Pamik T, Morgenthal K, Wienkoop S, Keerberg O, Weckwerth W, Kleczkowski LA, Fernie AR, Bauwe H: A cytosolic pathway for the conversion of hydroxypyruvate to glycerate during photorespiration in Arabidopsis. Plant Cell 2008, 20:2848-2859.

67. Renné $P$, Dressen U, Hebbeker U, Hille D, Flügge UI, Westhoff $P$, Weber APM: The Arabidopsis mutant $d c t$ is deficient in the plastidic glutamate/malate translocator DiT2. Plant J 2003, 35:316-331.

68. Palmieri L, Picault N, Arrigoni R, Besin E, Palmieri F, Hodges M: Molecular identification of three Arabidopsis thaliana mitochondrial dicarboxylate carrier isoforms: organ distribution, bacterial expression, reconstitution into liposomes and functional characterization. Biochem J 2008, 410:621-629.

69. Takahashi S, Bauwe H, Badger M: Impairment of the photorespiratory pathway accelerates photoinhibition of photosystem II by suppression of repair but not acceleration of damage processes in Arabidopsis. Plant Physiol 2007, 144:487-494.

70. Zheng ZY, Mosher SL, Fan BF, Klessig DF, Chen ZX: Functional analysis of Arabidopsis WRKY25 transcription factor in plant defense against Pseudomonas syringae. BMC Plant Biology 2007, 7.

71. Rizhsky L, Davletova S, Liang HJ, Mittler R: The zinc finger protein Zat12 is required for cytosolic ascorbate peroxidase 1 expression during oxidative stress in Arabidopsis. J Biol Chem 2004, 279:11736-11743.

72. Davletova S, Schlauch K, Coutu J, Mittler R: The zinc-finger protein Zat12 plays a central role in reactive oxygen and abiotic stress signaling in Arabidopsis. Plant Physiol 2005, 139:847-856.

73. Vogel JT, Zarka DG, Van Buskirk HA, Fowler SG, Thomashow MF: Roles of the CBF2 and ZAT12 transcription factors in configuring the low temperature transcriptome of Arabidopsis. Plant J 2005, 41:195-211.

74. Niwa $Y$, Ito S, Nakamichi N, Mizoguchi T, Niinuma K, Yamashino T, Mizuno T: Genetic linkages of the circadian clock-associated genes, TOC1, CCA1 and LHY, in the photoperiodic control of flowering time in Arabidopsis thaliana. Plant Cell Physiol 2007, 48:925-937.

75. Kant P, Gordon M, Kant S, Zolla G, Davydov O, Heimer YM, Chalifa-Caspi V, Shaked R, Barak S: Functional-genomics-based identification of genes that regulate Arabidopsis responses to multiple abiotic stresses. Plant Cell Environ 2008, 31:697-714.

76. Li XX, Duan XP, Jiang HX, Sun YJ, Tang YP, Yuan Z, Guo JK, Liang WQ, Chen L, Yin JY, Ma H, Wang J, Zhang DB: Genome-wide analysis of basic/ helix-loop-helix transcription factor family in rice and Arabidopsis. Plant Physiol 2006, 141:1167-1184.

77. Kang HG, Foley RC, Onate-Sanchez L, Lin CGT, Singh KB: Target genes for OBP3, a Dof transcription factor, include novel basic helix-loop-helix domain proteins inducible by salicylic acid. Plant J 2003, 35:362-372.

78. Vorwieger A, Gryczka C, Czihal A, Douchkov D, Tiedemann J, Mock HP Jakoby M, Weisshaar B, Saalbach I, Baumlein H: Iron assimilation and transcription factor controlled synthesis of riboflavin in plants. Planta 2007, 226:147-158

79. Lim CJ, Hwang JE, Chen H, Hong JK, Yang KA, Choi MS, Lee KO, Chung WS, Lee SY, Lim CO: Over-expression of the Arabidopsis DRE/CRT-binding transcription factor DREB2C enhances thermotolerance. Biochem Biophys Res Commun 2007, 362:431-436.

80. Lillo C, Lea US, Ruoff P: Nutrient depletion as a key factor for manipulating gene expression and product formation in different branches of the flavonoid pathway. Plant Cell Environ 2008, 31:587-601.

81. Kim JH, Kim BG, Park Y, Ko JH, Lim CE, Lim J, Lim Y, Ahn JH: Characterization of flavonoid 7-O-glucosyltransferase from Arabidopsis thaliana. Biosci Biotechnol Biochem 2006, 70:1471-1477.

82. Jones P, Messner B, Nakajima Jl, Schaffner AR, Saito K: UGT73C6 and UGT78D1, glycosyltransferases involved in flavonol glycoside biosynthesis in Arabidopsis thaliana. J Biol Chem 2003, 278:43910-43918.

83. Poppenberger B, Fujioka S, Soeno K, George GL, Vaistij FE, Hiranuma S, Seto H, Takatsuto S, Adam G, Yoshida S, Bowles D: The UGT73C5 of Arabidopsis thaliana glucosylates brassinosteroids. Proc Natl Acad Sci USA 2005, 102:15253-15258.

84. Yazaki $\mathrm{K}: \mathrm{ABC}$ transporters involved in the transport of plant secondary metabolites. FEBS Lett 2006, 580:1183-1191. 
85. Buer CS, Muday GK, Djordjevic MA: Flavonoids are differentially taken up and transported long distances in Arabidopsis. Plant Physiol 2007, 145:478-490

86. Klein $M$, Burla B, Martinoia E: The multidrug resistance-associated protein (MRP/ABCC) subfamily of ATP-binding cassette transporters in plants. FEBS Lett 2006, 580:1112-1122.

87. Lu YP, Li ZS, Drozdowicz YM, Hortensteiner S, Martinoia E, Rea PA: AtMRP2, an Arabidopsis ATP binding cassette transporter able to transport glutathione S-conjugates and chlorophyll catabolites: Functional comparisons with AtMRP1. Plant Cell 1998, 10:267-282.

88. Frelet-Barrand A, Kolukisaoglu HU, Plaza S, Ruffer M, Azevedo L, Hortensteiner S, Marinova K, Weder B, Schulz B, Klein M: Comparative mutant analysis of arabidopsis ABCC-type $A B C$ transporters: AtMRP2 contributes to detoxification, vacuolar organic anion transport and chlorophyll degradation. Plant Cell Physio/ 2008, 49:557-569.

89. Klein M, Geisler M, Suh SJ, Kolukisaoglu HU, Azevedo L, Plaza S, Curtis MD, Richter A, Weder B, Schulz B, Martinoia E: Disruption of AtMRP4, a guard cell plasma membrane $A B C C$-type $A B C$ transporter, leads to deregulation of stomatal opening and increased drought susceptibility. Plant J 2004, 39:219-236.

90. Kolukisaoglu HU, Bovet L, Klein M, Eggmann T, Geisler M, Wanke D, Martinoia E, Schulz B: Family business: the multidrug-resistance related protein (MRP) ABC transporter genes in Arabidopsis thaliana. Planta 2002, 216:107-119.

91. Schuler MA, Duan H, Bilgin M, Ali S: Arabidopsis cytochrome P450s through the looking glass: a window on plant biochemistry. Phytochem Rev 2006, 5:205-237.

92. Kusnierczyk A, Winge P, Jorstad TS, Troczynska J, Rossiter JT, Bones AM: Towards global understanding of plant defence against aphids timing and dynamics of early Arabidopsis defence responses to cabbage aphid (Brevicoryne brassicae) attack. Plant Cell Environ 2008, 31:1097-1115.

93. Pfalz M, Vogel H, Kroymann J: The gene controlling the indole glucosinolate modifier1 quantitative trait locus alters indole glucosinolate structures and aphid resistance in Arabidopsis. Plant Cell 2009, 21:985-999.

94. Bruce TJA, Matthes MC, Chamberlain K, Woodcock CM, Mohib A, Webster B, Smart LE, Birkett MA, Pickett JA, Napier JA: cis-Jasmone induces Arabidopsis genes that affect the chemical ecology of multitrophic interactions with aphids and their parasitoids. Proc Natl Acad Sci USA 2008, 105:4553-4558.

95. Manabe Y, Tinker N, Colville A, Miki B: CSR1, the sole target of imidazolinone herbicide in Arabidopsis thaliana. Plant Cell Physiol 2007 48:1658-1658.

96. Fode B, Siemsen T, Thurow C, Weigel R, Gatz C: The Arabidopsis GRAS protein SCL14 interacts with class II TGA transcription factors and is essential for the activation of stress-inducible promoters. Plant Cell 2008, 20:3122-3135.

97. Ehlting J, Sauveplane V, Olry A, Ginglinger JF, Provart NJ, Werck-Reichhart D: An extensive (co-)expression analysis tool for the cytochrome P450 superfamily in Arabidopsis thaliana. BMC Plant Biology 2008, 8:47.

98. Komives T, Gullner G: Phase I xenobiotic metabolic systems in plants. Z Naturforsch 2005, 60:179-185.

99. Frova C: The plant glutathione transferase gene family: genomic structure, functions, expression and evolution. Physiol Plant 2003, 119:469-479.

100. Basantani M, Srivastava A: Plant glutathione transferases - a decade falls short. Can J Bot/Rev Can Bot 2007, 85:443-456.

101. Queval G, Issakidis-Bourguet E, Hoeberichts FA, Vandorpe M, Gakiere B, Vanacker H, Miginiac-Maslow M, Van Breusegem F, Noctor G: Conditional oxidative stress responses in the Arabidopsis photorespiratory mutant cat2 demonstrate that redox state is a key modulator of daylengthdependent gene expression, and define photoperiod as a crucial factor in the regulation of $\mathrm{H}_{2} \mathrm{O}_{2}$-induced cell death. Plant J 2007, 52:640-657.

102. Sappl PG, Onate-Sanchez L, Singh KB, Millar AH: Proteomic analysis of glutathione S-transferases of Arabidopsis thaliana reveals differential salicylic acid-induced expression of the plant-specific phi and tau classes. Plant Mol Biol 2004, 54:205-219.

103. Jiang $Y Q$, Deyholos MK: Comprehensive transcriptional profiling of $\mathrm{NaCl}$ stressed Arabidopsis roots reveals novel classes of responsive genes. BMC Plant Biology 2006, 6.
104. Ezaki B, Suzuki M, Motoda H, Kawamura M, Nakashima S, Matsumoto H: Mechanism of gene expression of Arabidopsis glutathione S-transferase, AtGST1, and AtGST11 in response to aluminum stress. Plant Physiol 2004, 134:1672-1682.

105. Smith AP, Nourizadeh SD, Peer WA, Xu JH, Bandyopadhyay A, Murphy AS, Goldsbrough PB: Arabidopsis AtGSTF2 is regulated by ethylene and auxin, and encodes a glutathione S-transferase that interacts with flavonoids. Plant J 2003, 36:433-442.

106. Gachon CMM, Langlois-Meurinne M, Saindrenan P: Plant secondary metabolism glycosyltransferases: the emerging functional analysis. Trends Plant Sci 2005, 10:542-549.

107. Lim EK, Doucet CJ, Li Y, Elias L, Worrall D, Spencer SP, Ross J, Bowles DJ: The activity of Arabidopsis glycosyltransferases toward salicylic acid, 4hydroxybenzoic acid, and other benzoates. J Biol Chem 2002, 277:586-592.

108. Hong ZL, Zhang ZM, Olson JM, Verma DPS: A novel UDP-glucose transferase is part of the callose synthase complex and interacts with phragmoplastin at the forming cell plate. Plant Cell 2001, 13:769-779.

109. Sinlapadech T, Stout J, Ruegger MO, Deak M, Chapple C: The hyperfluorescent trichome phenotype of the brt1 mutant of Arabidopsis is the result of a defect in a sinapic acid: UDPG glucosyltransferase. Plant J 2007, 49:655-668.

110. Hou BK, Lim EK, Higgins GS, Bowles DJ: N-glucosylation of cytokinins by glycosyltransferases of Arabidopsis thaliana. J Biol Chem 2004, 279:47822-47832.

111. Gandia-Herrero F, Lorenz A, Larson T, Graham IA, Bowles DJ, Rylott EL, Bruce NC: Detoxification of the explosive 2,4,6-trinitrotoluene in Arabidopsis: discovery of bifunctional $O$ - and C-glucosyltransferases. Plant J 2008, 56:963-974.

112. Jackson RG, Kowalczyk M, Li Y, Higgins G, Ross J, Sandberg G, Bowles DJ: Over-expression of an Arabidopsis gene encoding a glucosyltransferase of indole-3-acetic acid: phenotypic characterisation of transgenic lines. Plant J 2002, 32:573-583.

113. Dean JV, Delaney SP: Metabolism of salicylic acid in wild-type, ugt74f1 and ugt74f2 glucosyltransferase mutants of Arabidopsis thaliana. Physiol Plant 2008, 132:417-425.

114. Quiel JA, Bender J: Glucose conjugation of anthranilate by the Arabidopsis UGT74F2 glucosyltransferase is required for tryptophan mutant blue fluorescence. J Biol Chem 2003, 278:6275-6281.

115. Lim CE, Ahn JH, Lim J: Molecular genetic analysis of tandemly located glycosyltransferase genes, UGT73B1, UGT73B2, and UGT73B3, in Arabidopsis thaliana. J Plant Biol 2006, 49:309-314.

116. Langlois-Meurinne M, Gachon CMM, Saindrenan P: Pathogen-responsive expression of glycosyltransferase genes UGT73B3 and UGT73B5 is necessary for resistance to Pseudomonas syringae pv tomato in Arabidopsis. Plant Physiol 2005, 139:1890-1901.

117. Omote H, Hiasa M, Matsumoto T, Otsuka M, Moriyama Y: The MATE proteins as fundamental transporters of metabolic and xenobiotic organic cations. Trends Pharmacol Sci 2006, 27:587-593.

118. Li LG, He ZY, Pandey GK, Tsuchiya T, Luan S: Functional cloning and characterization of a plant efflux carrier for multidrug and heavy metal detoxification. J Biol Chem 2002, 277:5360-5368.

119. Vanderauwera $S$, Zimmermann $P$, Rombauts $S$, Vandenabeele $S$, Langebartels C, Gruissem W, Inze D, Van Breusegem F: Genome-wide analysis of hydrogen peroxide-regulated gene expression in Arabidopsis reveals a high light-induced transcriptional cluster involved in anthocyanin biosynthesis. Plant Physiol 2005, 139:806-821.

120. Sakuma Y, Maruyama K, Qin F, Osakabe Y, Shinozaki K, YamaguchiShinozaki K: Dual function of an Arabidopsis transcription factor DREB2A in water-stress-responsive and heat-stress-responsive gene expression. Proc Natl Acad Sci USA 2006, 103:18822-18827.

121. Salk Institute Genomic Analysis Laboratory (SIGnAL). [http://signal.salk. edu/cgi-bin/tdnaexpress].

122. European Arabidopsis Stock Centre (NASC). [http://arabidopsis.info/].

123. Irizarry RA, Hobbs B, Collin F, Beazer-Barclay YD, Antonellis KJ, Scherf U, Speed TP: Exploration, normalization, and summaries of high density oligonucleotide array probe level data. Biostatistics 2003, 4:249-264.

124. The R-project for statistical computing. [http://www.r-project.org/].

125. Smyth G: Linear models and empirical Bayes methods for assessing differential expression in microarray experiments. Statistical Applications in Genetics and Molecular Biology 2004, 3, Article 3. 
126. Storey JD: A direct approach to false discovery rates. J R Stat Soc Ser B 2002, 64:479-498.

127. Benjamini $Y$, Hochberg $Y$ : Controlling the false discovery rate - a practical and powerful approach to multiple testing. J R Stat Soc Ser B 1995, 57:289-300.

128. The Arabidopsis Information Service (TAIR). [http://www.arabidopsis.org].

129. AraCyc. [http://www.arabidopsis.org/biocyc/].

130. Kyoto Encyclopedia of Genes and Genomes (KEGG). [http://www. genome.ad.jp/kegg/

131. Expert Protein Analysis System (ExPASy). [http://www.expasy.org].

132. The Gene Ontology Database. [http://amigo.geneontology.org/cgi-bin/ amigo/go.cgi].

133. Liang YS, Choi YH, Kim HK, Linthorst HJM, Verpoorte R: Metabolomic analysis of methyl jasmonate treated Brassica rapa leaves by 2dimensional NMR spectroscopy. Phytochemistry 2006, 67:2503-2511.

134. Wong JWH, Cagney G, Cartwright HM: SpecAlign - processing and alignment of mass spectra datasets. Bioinformatics 2005, 21:2088-2090.

135. Mevik BH, Wehrens R: The pls package: Principal component and partial least squares regression in R. J Stat Softw 2007, 18:2.

doi:10.1186/1471-2164-11-190

Cite this article as: Kissen et al: Transcriptional profiling of an FdGOGAT1/GLU1 mutant in Arabidopsis thaliana reveals a multiple stress response and extensive reprogramming of the transcriptome. $B M C$ Genomics 2010 11:190.

\section{Submit your next manuscript to BioMed Central} and take full advantage of:

- Convenient online submission

- Thorough peer review

- No space constraints or color figure charges

- Immediate publication on acceptance

- Inclusion in PubMed, CAS, Scopus and Google Scholar

- Research which is freely available for redistribution

Submit your manuscript at www.biomedcentral.com/submit
C Biomed Central 